\title{
Early hypogenic carbonic acid speleogenesis in unconfined limestone aquifers by upwelling deep-seated waters with high $\mathrm{CO}_{2}$ concentration: a modelling approach
}

\author{
Franci Gabrovšek ${ }^{1}$ and Wolfgang Dreybrodt ${ }^{1,2}$ \\ ${ }^{1}$ Karst Research Institute ZRC SAZU, Titov trg 2, 6230 Postojna, Slovenia \\ ${ }^{2}$ Faculty of Physics and Electrical Engineering, University of Bremen, Germany
}

Correspondence: Franci Gabrovšek (gabrovsek@zrc-sazu.si) and Wolfgang Dreybrodt (dreybrodt@t-online.de)

Received: 14 September 2020 - Discussion started: 16 October 2020

Revised: 15 February 2021 - Accepted: 28 April 2021 - Published: 28 May 2021

\begin{abstract}
Here we present results of digital modelling of a specific setting of hypogenic carbonic acid speleogenesis (CAS). We study an unconfined aquifer where meteoric water seeps through the vadose zone and becomes saturated with respect to calcite when it arrives at the water table. From below, deep-seated water with high $p_{\mathrm{CO}_{2}}$ and saturated with respect to calcite invades the limestone formation by forced flow. Two flow domains arise that host exclusively water from the meteoric or deep-seated source. They are separated by a water divide. There by dispersion of flow, a fringe of mixing arises and widening of the fractures is caused by mixing corrosion (MC). The evolution of the cave system is determined by its early state. At sites with high rates of fracture widening, regions of higher hydraulic conductivity are created. They attract flow and support one-by-one mixing with maximal dissolution rates. Therefore, the early evolution is determined by karstification originating close to the input of the upwelling water and at the output at a seepage face. In between these regions, a wide fringe of moderate dissolution is present. In the later stage of evolution, this region is divided by constrictions that originate from statistical variations of fracture aperture widths that favour high dissolution rates and focus flow into this region. This MC-fringe instability is an intrinsic property of cave evolution and is present in all scenarios studied. We have investigated the influence of defined regions with higher fracture aperture widths. These determine the cave patterns and suppress MC-fringe instabilities. We have discussed the influence of the ratio of upwelling water flux rates on the rates of meteoric water. This ratio specifies the position of the mixing fringe and conse-
\end{abstract}

quently that of the cave system. In a further step, we have explored the influence of time-dependent meteoric recharge. Furthermore, we have modelled scenarios where waters are undersaturated with respect to calcite. These findings give important insight into mechanisms of CAS in a special setting of unconfined aquifers. They also have implications for the understanding of corresponding sulfuric acid speleogenesis (SAS).

\section{Introduction}

Hydrochemical digital models of speleogenesis are powerful tools for understanding the physical and chemical processes that determine the evolution of caves. Initial models of the evolution of 1-D fractures (Dreybrodt, 1990; Palmer, 1991; Dreybrodt, 1996) were soon extended to different manifestations of fracture networks within 2D and 3D domains (Groves and Howard, 1994; Siemers and Dreybrodt, 1998; Kaufmann et al., 2010; Kaufmann, 2016; Li et al., 2020). An example range of hypothetical hydrological, structural and geochemical settings was envisioned in order to understand the basic speleogenetic mechanisms (Birk et al., 2003; Kaufmann, 2003; Dreybrodt et al., 2005; Gabrovšek and Dreybrodt, 2010). The models have also been used for a processbased interpretation of real situations (Kaufmann and Romanov, 2019). The development of the models has been guided by theoretical insights based on small-scale detailed studies of dissolution front propagation and fingering (Hanna and Rajaram, 1998; Cheung and Rajaram, 2002; Szymczak 
and Ladd, 2009; Dreybrodt and Gabrovšek, 2019). Most of the models simulate epigene speleogenesis governed by the aggressive solution from the surface.

In the last 2 decades hypogenic caves have attracted broad interest in the karst community, highlighted in the recent book "Hypogene Karst regions and caves of the world" (Klimchouk et al., 2017). The book gives a wide overview of hypogenic caves worldwide.

There are two concepts of the evolution of hypogenic caves.

1. Klimchouk (2007, 2016) suggests a hydrological approach, stating that "the formation of solutionenlarged permeability structures (void-conduit systems) is caused by fluids that recharge the cavernous zone from below, driven by hydrostatic pressure or other sources of energy, independent of direct recharge from the overlying or immediately adjacent surface". This definition applies to large gypsum cave systems of western Ukraine. These caves motivated a series of studies modelling artesian hypogenic speleogenesis (Birk et al., 2003, 2005; Rehrl et al., 2008; Kaufmann et al., 2014; $\mathrm{Li}$ et al., 2020). Thermal water saturated with respect to calcite that rises from below gains renewed aggressiveness when cooling and may create caves. Such scenarios have been modelled by several authors (Andre and Rajaram, 2005; Rajaram et al., 2009; Chaudhuri et al., 2009, 2013; Gong et al., 2019) and also fit to the speleogenetic concept as defined by Klimchouk.

2. Palmer $(2000,2007)$ suggests a geochemical view, which defines hypogenic caves as "those formed by water in which the aggressiveness has been produced at depth beneath the surface, independent of surface or soil $\mathrm{CO}_{2}$ or other near-surface acid sources." This definition results from observations in Carlsberg Caverns, New Mexico, USA, where sulfuric acid dominates dissolution of limestone, and from caves in the Black Hills, South Dakota, USA, that are created by carbonic acid speleogenesis (Palmer, 2017).

Dissolution by sulfuric acid (Palmer, 2013) can occur where $\mathrm{H}_{2} \mathrm{~S}$-bearing deep-seated waters rise from below and mix with oxygenated groundwater. There, $\mathrm{H}_{2} \mathrm{~S}$ is oxidized by bacterial aid to sulfuric acid that dissolves limestone, releasing $\mathrm{CO}_{2}$ for further dissolution of carbonate rock. This speleogenetic process, termed sulfuric acid speleogenesis (SAS), has created large caves, e.g. Carlsbad Caverns in the Guadalupe reef complex in the United States and the Frasassi cave system in central Italy.

Carbonic acid operates also as a hypogenic agent that is produced at depth, e.g. by thermal decomposition of carbonate rocks. This way $\mathrm{CO}_{2}$-containing water with high $p_{\mathrm{CO}_{2}}$ up to $1 \mathrm{~atm}$ can intrude into upper aquifers, especially in areas of young volcanism, point-wise or disperse, depending on geologic/structural conditions (Jeong et al., 2005; Palmer,
2007; Klimchouk, 2013; Audra and Palmer, 2015). $\mathrm{CO}_{2}$ may also stem from oxidation of deep-seated organic compounds, as they are abundant near hydrocarbon fields (Klimchouk, 2019).

It should be mentioned that modelling of dissolution of calcium carbonate in mixing zones in karst systems has been studied in general alternative models by other groups successfully. This approach decouples the solute transport and chemical reaction in the mixing fringes (De Simoni et al., 2007). Mixing of freshwater and seawater in coastal aquifers and the resulting evolution of porosity have also been modelled (Romanov and Dreybrodt, 2006; Laabidi and Bouhlila, 2015). However, to our knowledge such an approach has not been used to model problems of SAS or CAS.

In this work, we focus on a specific hypothetical case of hypogenic carbonic acid speleogenesis (CAS). We study an unconfined aquifer where meteoric water seeps through the vadose zone and becomes saturated with respect to calcite when it arrives at the water table. From below, deep-seated water with high $p_{\mathrm{CO}_{2}}$ and saturated with respect to calcite invades the limestone formation by forced flow. Mixing corrosion acts in the regions where these waters mix, creating cave conduits. From the results, we also discuss analogies with SAS and the problems that arise in modelling of SAS.

\section{The model}

\subsection{Modelling domain of an unconfined aquifer with mixing of surface and deep-seated waters}

As the first step, we discuss the modelling domains and settings that determine hypogenic karstification. Figure 1 shows the settings of an unconfined aquifer. With respect to surface water leaking to the aquifer, this setting is similar to the geology of Wind Cave in the Black Hills, South Dakota, USA (Palmer, 2017). In the abstract, he states that "Cave enlargement depended mainly on diffuse recharge through overlying sandstone, mixing with lateral inflow through carbonate outcrops."

This stresses the geological relevance of our model.

A net of fracture conjunctions as depicted in Fig. 1b, each $2 \mathrm{~m}$ long and $1 \mathrm{~m}$ wide, is connected to form a rectangular array that presents a vertical 2D section of an unconfined aquifer of a selected depth and length. To each fracture, individually a selected aperture width is assigned. This way a net with a log-normal distribution of aperture widths as shown in Fig. 1c is created. The following boundary conditions are applied: at the top of the domain, we impose a constant input, $q$, of water to each fracture to simulate the recharge by meteoric water. To each input fracture, a defined $\mathrm{Ca}$ concentration and $p_{\mathrm{CO}_{2}}$ of the inflowing water are assigned.

On the left-hand side, we impose a no-flow condition to model a water divide. The right-hand side presents the outflow of water where each fracture is open to the atmosphere 

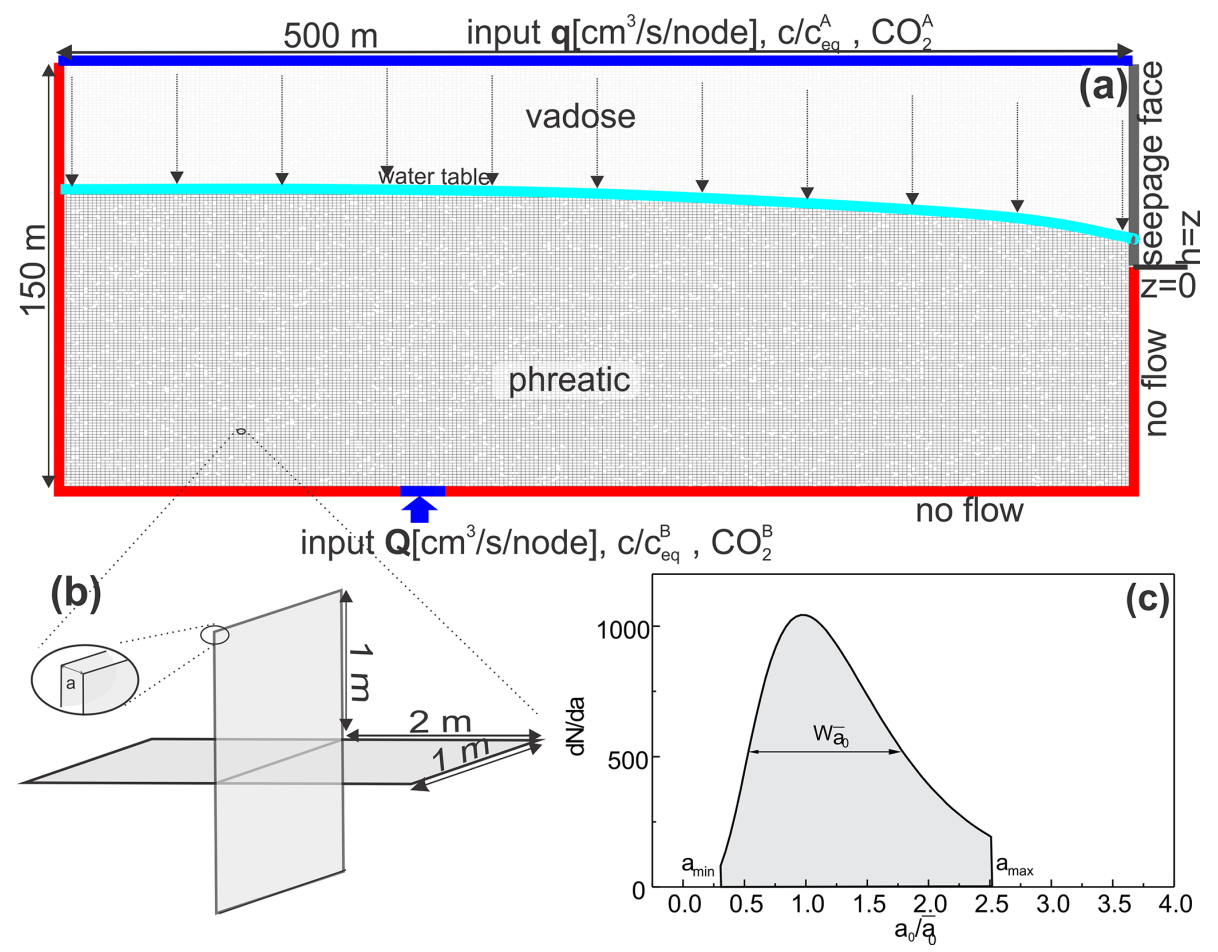

Figure 1. (a) Two-dimensional fracture network presenting a vertical cross section through an unconfined aquifer. The length of the domain is $500 \mathrm{~m}$, and the depth is $150 \mathrm{~m}$. Fracture spacing is $2 \times 1 \mathrm{~m}^{2}$ as depicted in (b). Input $q, \mathrm{~cm}^{3} \mathrm{~s}^{-1}$ node ${ }^{-1}$, at the top is evenly distributed meteoric water percolating to the water table. When it arrives there, it has become saturated with respect to calcite and $p_{\mathrm{CO}_{2}}$. At the bottom of the domain, deep-seated upwelling water enters with prescribed flow $Q, \mathrm{~cm}^{3} \mathrm{~s}^{-1}$ node $^{-1}$ by forced flow. Due to dissolution of limestone on its way from below, this water is saturated with respect to calcite and high $p_{\mathrm{CO}_{2}}$. The water flows to a seepage face located above height $z=0$. Red border denotes no-flow conditions, and blue border denotes input of prescribed flow. Each fracture has an initial aperture width $a$, which is selected from a truncated log-normal distribution, shown in (c).

in the upper part (seepage face). The lower region is at the no-flow condition. Therefore, a water table arises that divides the aquifer into a vadose zone (light grey) and a phreatic zone (dark grey). The bottom boundary of the modelling domain is regarded as impermeable (no-flow condition, red), with the exception of a defined region (blue) where waters from the depth with defined chemical composition invade the aquifer with constant flow, $Q$, into each fracture. For each fracture where water enters into the aquifer, $\mathrm{Ca}$ concentration and $p_{\mathrm{CO}_{2}}$ are selected. In a pure $\mathrm{CaCO}_{3}-\mathrm{CO}_{2}-\mathrm{H}_{2} \mathrm{O}$ solution, these two parameters define all its chemical properties.

There is an important general property of flow under such boundary conditions. Whenever Darcy flow originates from different recharging sources, in our case, meteoric water to the water table and upwelling deep water from below, each source creates a flow domain that hosts only water originating from the corresponding recharge source. Flow domains of different origins of waters are separated by a water divide. The waters of differing origin do not mix. Only at the water divide is mixing possible caused by dispersion of flow into the fractures close to the water divide.

Figure 2 presents an illustration. Water entering from below with equilibrium concentration $c_{\mathrm{eq}}^{B}$ is coloured in red, whereas recharge from the top with equilibrium concentration $c_{\mathrm{eq}}^{a}$ is coloured in blue. Clearly two flow domains are visible. Water entering from below occupies the lower red region, expanding from its input to the outflow at the seepage face. Water from the top (red) that recharges at the seepage face floats on the flow domain below. At the border between the two domains a fringe is visible with rainbow colours that indicate the mixing zone. The colours symbolize the equilibrium concentrations of the mixed solutions and therefore also the mixing ratio as depicted by the colour code. Red is $V_{A} / V_{B}=0 / 1$, green $V_{A} / V_{B}=1 / 1$, and dark blue $V_{A} / V_{B}=1 / 0$.

The position of this mixing zone depends on the input ratio $q / Q$. With increasing ratio, the mixing zone shifts downwards. Therefore, at a constant inflow from below but varying recharge of meteoric water as occurs likely during the evolution of caves, the mixing zone fluctuates up and down. When the water entering into the limestone aquifer is undersaturated with respect to calcite, we find two regions of limestone dissolution. Each of them extends from the input into the corresponding flow domains but stays limited there. There is also dissolution in the mixing zone, where waters that have become saturated mix. However, even in the case 


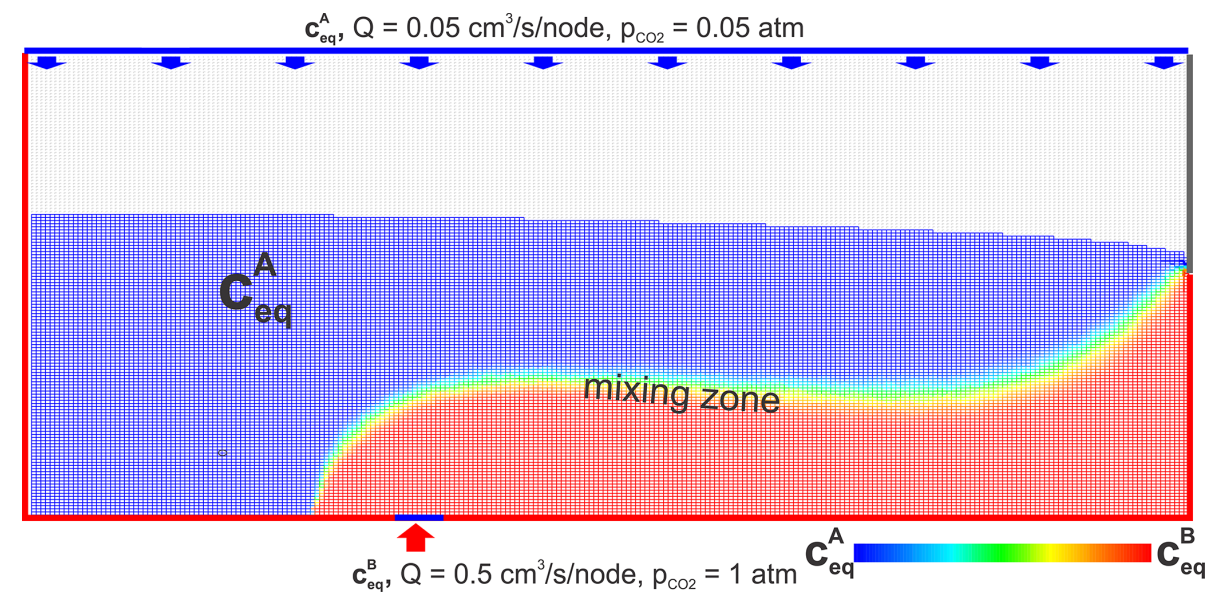

Figure 2. Visualization of the mixing zone. Two types of waters, one with calcium equilibrium concentration $c_{\mathrm{eq}}^{B}$ and the other with equilibrium concentration $c_{\mathrm{eq}}^{b}$, invade the aquifer. Flow domains red and blue are separated by a water divide. There dispersive mixing takes place, and the equilibrium concentration of the mixed solution is between the values $c_{\mathrm{eq}}^{B}$ and $c_{\mathrm{eq}}^{A}$ (see Fig. 3). This is depicted by a colour code with red for the highest concentration $c_{\mathrm{eq}}^{B}$ decreasing down through the optical spectrum to dark blue for concentration $c_{\mathrm{eq}}^{A}$. This way the colours indicate the degree of mixing. The green region hosts one-by-one mixing.

when the input waters are saturated with respect to calcite, mixing corrosion (MC) is active in the mixing fringe.

\subsection{The digital model}

All information concerning the numerical scheme and the model is reported in the previous literature: details of the digital model are given by Dreybrodt et al. (2005), Gabrovšek and Dreybrodt (2010) and Dreybrodt and Gabrovšek (2019).The extension to unconfined aquifers is described in detail in Gabrovšek and Dreybrodt (2001). The 1-D transport-dissolution model is reported in detail by Dreybrodt (1996). Therefore, we give only brief essentials here.

The simulation in time proceeds through a series of steady states because the timescale of fracture widening by dissolution is much larger than that of transient flow and transport. At each time step, stationary solutions of flow, transport, and dissolution rates are used to calculate the change in fracture geometry within the time step. We first calculate the hydrodynamics, based on mass conservation at the fracture intersections, the head loss relation for laminar flow along the fractures and the given boundary conditions. This yields a set of linear equations for the junction heads, which is solved by a preconditioned conjugate gradient method. To account for the free upper boundary of the unconfined aquifer, the calculation of heads is wrapped into an iterative procedure seeking that the head of junctions at the water table is equal to their elevation above the base level (Gabrovšek and Dreybrodt, 2001).

We specify the calcium concentration $c_{\text {in }}$ and $p_{\mathrm{CO}_{2}}$ of the inflow solution at all input points. From these the equilibrium concentration, $c_{\mathrm{eq}}$, with respect to calcite is calculated for closed system conditions with respect to $\mathrm{CO}_{2}$. This way
MC is included automatically. We calculate the dissolution rates in the fracture draining the input points by the rate law $F(c)=k_{1}\left(1-c / c_{\mathrm{eq}}\right)$ with $k_{1}=4 \times 10^{-11} \mathrm{~mol} \mathrm{~cm}^{-2} \mathrm{~s}^{-1}$ for $c<0.9 c_{\mathrm{eq}}$ (Dreybrodt et al., 2005; Buhmann and Dreybrodt, 1985). For $c>0.9 c_{\text {eq }}$ a non-linear rate law $F(c)=$ $k_{4}\left(1-c / c_{\text {eq }}\right)^{4}$ with $k_{4}=4 \times 10^{-8} \mathrm{molcm}^{-2} \mathrm{~s}^{-1}$ is applied (Svensson and Dreybrodt, 1992; Eisenlohr et al., 1999). Next, we use the 1-D transport-dissolution model (Dreybrodt, 1996) to calculate the calcium concentration profile along all fractures, including the concentration of the solution leaving them. By following the order of decreasing heads, we select all nodes where the concentrations of the inflowing solutions are known. We assume complete mixing of these solutions in the junctions before they enter into the conduits transporting the flow away. We repeat this procedure until the input concentrations for all fractures are determined. From this, the new profiles of the fractures after a time step $\Delta t$ are obtained by applying the rate laws of dissolution. Then, the new flow rates are calculated, and we repeat the entire procedure to obtain the temporal evolution of the net until some defined condition is met.

\section{Mixing corrosion}

In our standard scenario, we assume that the meteoric water after percolating through the vadose zone has become saturated with respect to calcite when it reaches the water table. The upwelling water on its way from below has also reached saturation. Therefore widening of fractures by dissolution of limestone is possible only in the mixing zone by mixing corrosion (MC). For better understanding, mixing corrosion in the most general case is explained as follows. 


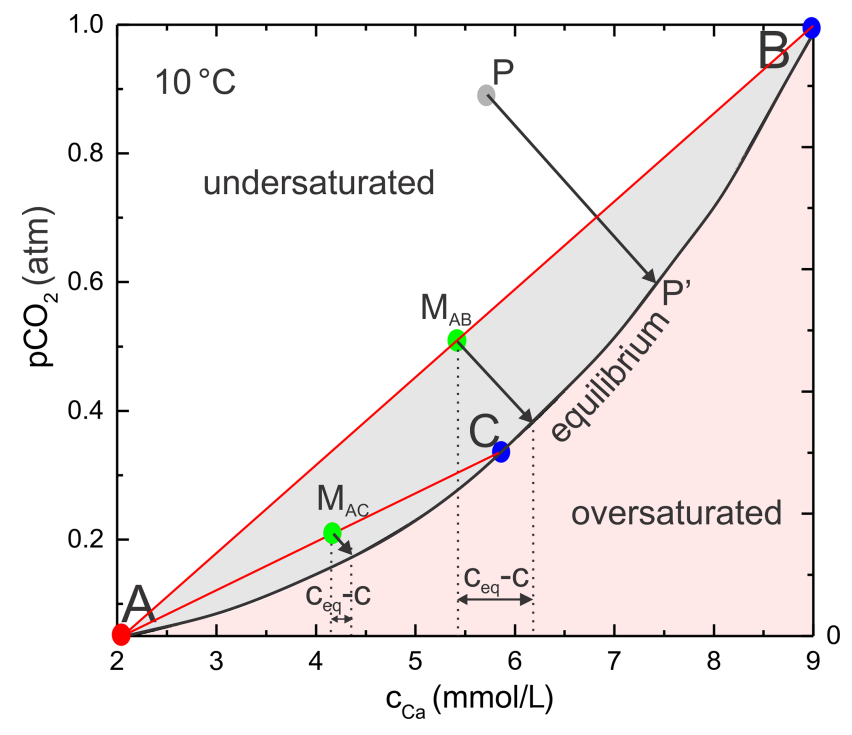

Figure 3. Processes in mixing corrosion (MC); see text.

Figure 3 depicts a plot of the $\mathrm{Ca}$ equilibrium concentration in its relation to the $p_{\mathrm{CO}_{2}}$ in the solution. Whether a $\mathrm{H}_{2} \mathrm{O}-\mathrm{CO}_{2}-\mathrm{CaCO}_{3}$ solution is dissolving calcite can be judged from this equilibrium line. The equilibrium line (black) is given by thermodynamics as (Dreybrodt, 1988) $c_{\mathrm{eq}}=A(T) p_{\mathrm{CO}_{2}}^{1 / 3}$, where $T$ is the temperature of the solution and $p_{\mathrm{CO}_{2}}$ is the partial pressure of $\mathrm{CO}_{2}$ in equilibrium with the solution. $A(T)$ is a constant depending on temperature only. $A(T)=11.3,9.45$, and $7.93 \mathrm{mmolL}^{-1}(\mathrm{~atm})^{-1 / 3}$ at 10 , 20 , and $30^{\circ} \mathrm{C}$ respectively.

The processes in $\mathrm{MC}$ are illustrated for $T=10^{\circ} \mathrm{C}$ in Fig. 3. The chemical composition of each solution in a $\mathrm{H}_{2} \mathrm{O}$ $\mathrm{CO}_{2}-\mathrm{CaCO}_{3}$ system is defined by the $\left(c_{\mathrm{Ca}}, p_{\mathrm{CO}_{2}}\right)$ coordinates. Each solution with chemical composition as given by point $P$ above the equilibrium line (black) is undersaturated with respect to calcite, whereas each point below the black equilibrium line is oversaturated, and calcite can be precipitated from such a solution. Dissolution in fractures proceeds under closed system conditions where for each $\mathrm{CaCO}_{3}$ unit dissolved one molecule of $\mathrm{CO}_{2}$ is removed from the solution. The straight black arrows depict the reaction pathway under closed system conditions as used in all our scenarios. Equilibrium with respect to calcite is obtained, for example, when the line from $P$ reaches point $P^{\prime}$.

Classical MC as a special case is defined when both the mixing solutions $\mathrm{A}$ and $\mathrm{B}$ or $\mathrm{C}$ are saturated with respect to calcite. Due to the curvature of the equilibrium line, the mixed solutions $M_{\mathrm{AB}}$ and $M_{\mathrm{AC}}$ on the corresponding mixing lines (red) are undersaturated and can dissolve calcite. The amount of $\mathrm{CaCO}_{3}$ dissolved can be read easily from the dotted arrow between the vertical dotted lines for the mixed solutions. To calculate $c_{\mathrm{eq}}$, evolving from any point $P, M_{\mathrm{AB}}$, or $M_{\mathrm{AC}}$, one has to find the intersection of the reaction path lines with the equilibrium curve. This yields a cubic equation for $c_{\mathrm{eq}}$.

\section{Standard scenario: pure mixing corrosion}

Figure 4 illustrates karstification of our standard scenario. The colour code depicts the rate of fracture widening in $\mathrm{cm} \mathrm{kyr}^{-1}$. Red is the maximal rate of $10 \mathrm{~cm} \mathrm{kyr}^{-1}$, and black is zero. The aperture widths of the fractures are shown by the bar code. The vadose zone is shown in light grey and the phreatic zone in black (no dissolution) or in colour (dissolution active).

Dissolution is active by mixing corrosion in the fringe where meteoric water and water from below mix (see also Figs. 2 and 3). In the beginning (Fig. 4a), a fringe of moderate dissolution rates increases the hydraulic conductivity in this region.

After 500 years (Fig. 4b) high dissolution rates are seen (orange) close to the input region of hypogenic water. Below that region of enhanced dissolution, one finds black widened fractures where dissolution has stopped. Evidently, the mixing zone due to the change in hydraulic properties has moved upwards. In the middle section, the region of mixing has become wider. Close to the exit of water dissolution is restricted to a narrow band with high dissolution rates.

After 5000 years (Fig. 4c) the region of dissolution has moved further upwards, leaving a region of widened fractures below (black). A main channel has formed to which dissolution is restricted. It widens uniformly and stays stable, as can be seen at 30000 years of evolution (Fig. 4d).

This is also illustrated in Fig. 5, which shows rates of fracture widening (green) in $\mathrm{cm} \mathrm{yr}^{-1}$ and the aperture widths (red) of the horizontal fractures along the vertical transects $p_{1}, p_{2}$, and $p_{3}$ as depicted in Fig. 4a. Although there is some variation in the fracture widening, its region is restricted to a depth of 100 to $113 \mathrm{~m}$, where the rates stay almost constant in time with maximum rates of about several $\mathrm{cm} \mathrm{kyr}^{-1}$. Therefore, the aperture widths increase linearly in time to a width of about $50 \mathrm{~cm}$ after 30000 years.

To explore the influence of the $p_{\mathrm{CO}_{2}}$ in the upwelling water, we performed a simulation with $p_{\mathrm{CO}_{2}}=0.2 \mathrm{~atm}$ and everything else as in the standard (not shown). The result is very similar to the standard. However, due to the smaller $\left(c-c_{\mathrm{eq}}\right)=0.1 \mathrm{mmolL}^{-1}$ at $0.2 \mathrm{~atm}$ (see Fig. 3), dissolution rates are reduced by almost 1 order of magnitude compared to $0.8 \mathrm{mmol} \mathrm{L}^{-1}$ at $1 \mathrm{~atm}$ (see Fig. 3). Consequently, the evolution to similar conduit (fracture) dimensions is delayed accordingly.

\section{Influence of the ratio $q / Q$}

As already stated, the position of the mixing fringe depends on the input ratio $q / Q$. Therefore, we have studied the evolution with three different recharge rates of rainwater cor- 

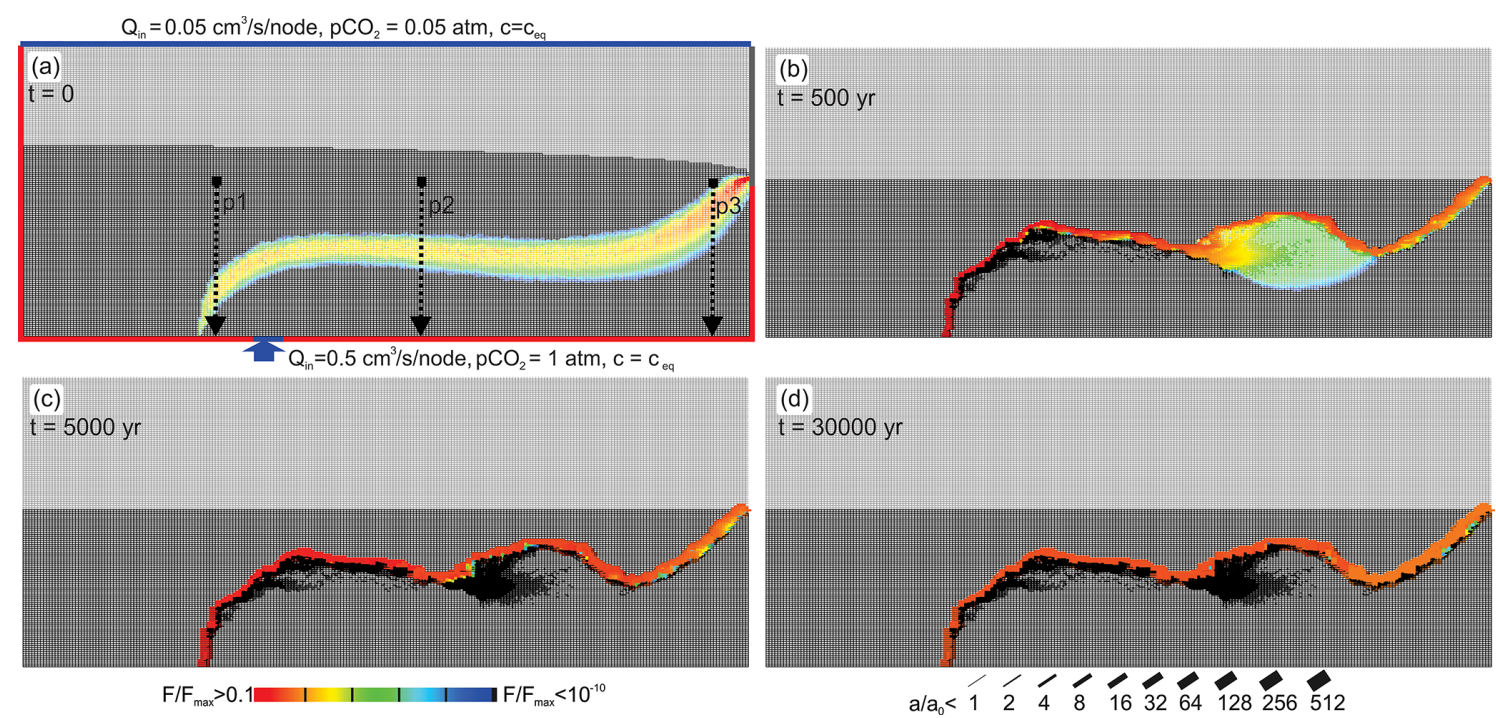

Figure 4. Temporal evolution of the standard scenario with MC exclusively. The colour code depicts rate, $F$, of fracture widening divided by the maximal widening $F_{\max }=10 \mathrm{~cm} \mathrm{kyr}^{-1}$ in the net. Aperture widths, a, of fractures are shown by a bar code in units of $a_{0}$, the initial average aperture width. After 5000 years the pattern is stable in time, and all fractures widen with rates almost constant in time. $P_{1}, P_{2}$, and $P_{3}$ are the positions of the transects of fracture aperture widths and rates of fracture widening shown in Fig. 5.
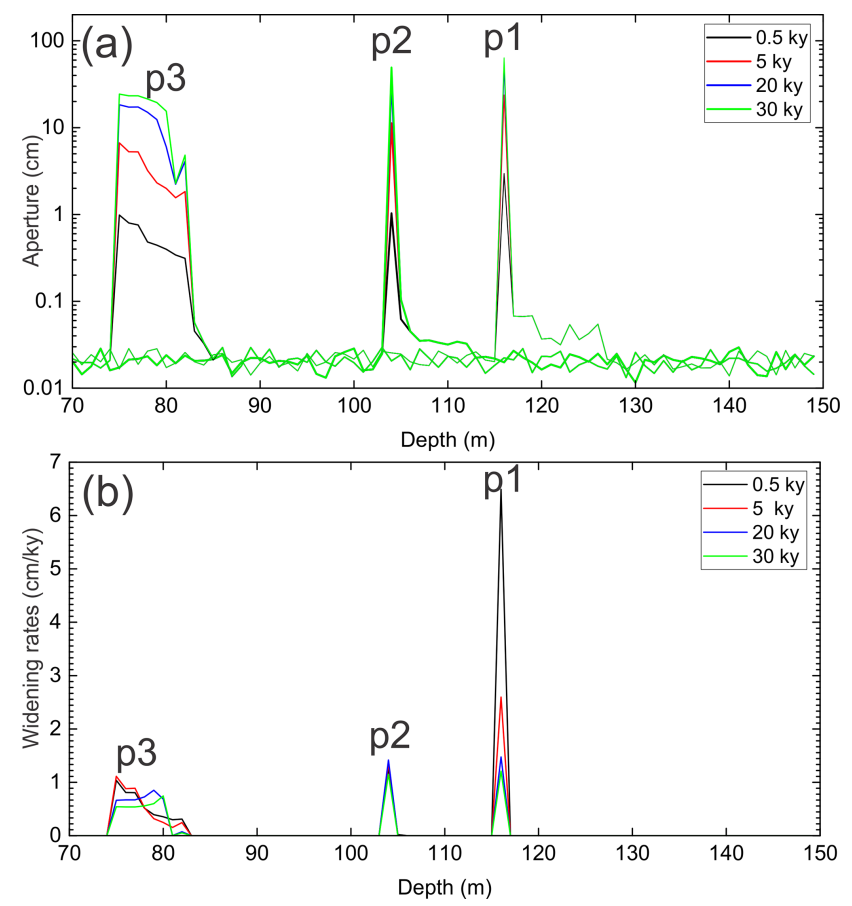

Figure 5. Transects of aperture widths and rates of widening of the horizontal fractures along the positions $p_{1}, p_{2}$, and $p_{3}$ in Fig. 4 a.

responding to 400,800 , and $1600 \mathrm{~mm} \mathrm{yr}^{-1}$ and constant input of hypogenic water from below. Figure $6 \mathrm{a}-\mathrm{c}$ exhibit the distribution of dissolution rates and fracture aperture widths after 44000 years. In all cases, one finds a fringe of karstification that is related to the location of the mixing zone.
With increasing recharge by meteoric water, this fringe is shifted downwards. Figure 7 depicts the profiles of the aperture width of the horizontal fractures close to the input of hypogenic water and close to the output at the spring. The profiles of aperture widths are very similar for all three cases, because the mixing of the waters does not depend on the position of the mixing zone.

\section{Standard scenario: meteoric recharge changes in time}

In all cases treated so far we have assumed that meteoric recharge is constant in time. This assumption is not realistic. In nature, meteoric recharge does fluctuate, and consequently the location of the mixing fringe will change its position accordingly. Therefore karstification may no longer be limited to the initial narrow fringe but could also be active between the fringe positions of maximal, $Q_{\max }$, and minimal, $Q_{\min }$, meteoric recharge.

To reveal the evolution under such conditions, we studied the following scenarios. In the first, meteoric recharge is low, at $400 \mathrm{~mm} \mathrm{yr}^{-1}$ during the first 10000 years of evolution. Then recharge is switched to a high value of $1600 \mathrm{~mm} \mathrm{yr}^{-1}$. In the second scenario we start with the high recharge and switch to the low one after 10000 years. The results are shown in Fig. 8. The panels on the left-hand side illustrate the temporal evolution when the initial input is low. In the beginning, the mixing zone is close to the water table due to the small input of rainwater. Dissolution and correspondingly widening of the fractures are restricted to this region, which gains higher hydraulic conductivity than its neighbouring re- 
$\mathrm{pCO}_{2}=0.05 \mathrm{~atm}, \mathrm{c}=\mathrm{C}_{\mathrm{ee}}$
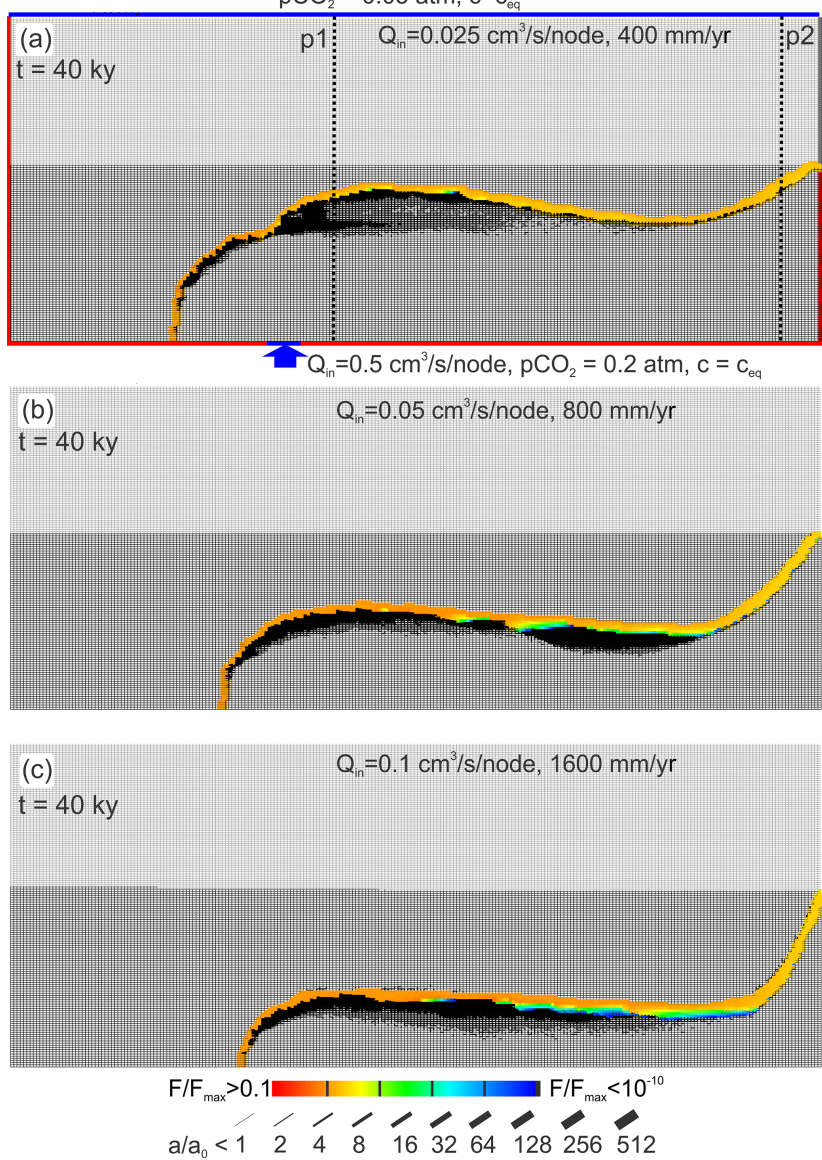

Figure 6. Cave pattern after 40000 years for various recharge rates $Q$ : (a) $400 \mathrm{~mm} \mathrm{yr}^{-1}$, (b) $800 \mathrm{~mm} \mathrm{yr}^{-1}$, and (c) $1600 \mathrm{~mm} \mathrm{yr}^{-1}$ and constant recharge from below. With increasing recharge, the flow domain of meteoric water increases, and the fringe of mixing is shifted downwards. To show that even low $p_{\mathrm{CO}_{2}}$ in the upwelling water creates substantial karstification, we have used $p_{\mathrm{CO}_{2}}=0.2 \mathrm{~atm}$. Everything else as in the standard scenario.

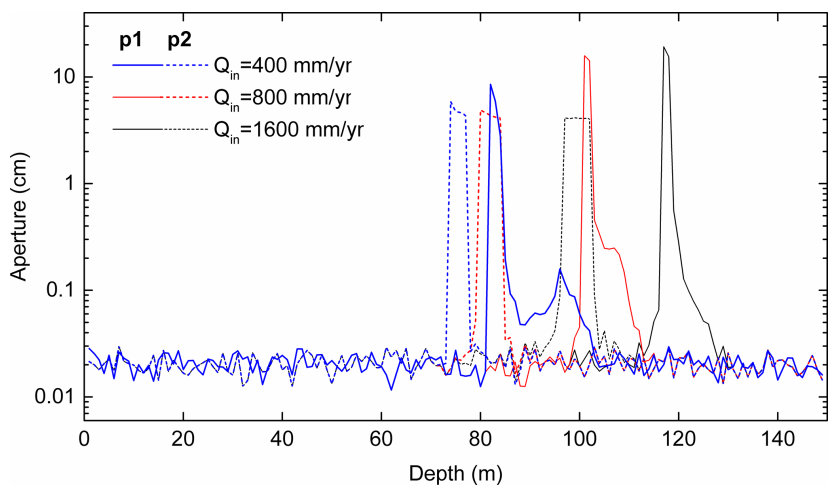

Figure 7. Vertical profiles of horizontal fracture aperture widths along positions p1 and p2 shown in Fig. 6 after 40000 years of evolution. gions. This focuses flow of both the flow domain from the input below and the flow domain of the rainwater into the region of increased hydraulic conductivity during the first 500 years. A channel develops, reaching the dropping water table, and then after looping down it approaches the spring. This channel attracts all flow, and even when the model switches to higher input of rainwater after 10000 years the further evolution proceeds along this channel as depicted in the lowest panel after 15000 years.

The right-hand side panels show the temporal evolution when the initial input of meteoric water is high at $1600 \mathrm{~mm} \mathrm{yr}^{-1}$ and then after 10000 years switches to the low value of $400 \mathrm{~mm} \mathrm{yr}^{-1}$. Due to the high input the mixing zone is forced deeper into the aquifer. In analogy to the left-hand side scenario in this region, high conductivity is created that further determines the evolution of a channel deeper in the aquifer that does not change its position even when the input of rain later is reduced drastically after 10000 years.

In summary: the evolution of caves is highly determined by its initial phase of evolution and restricted to the regions where widening of fractures occurs initially. This is due to a positive feedback loop that exists initially. Widening of fractures attracts flow, increasing dissolution rates that cause widening of fractures and so on. However, this feedback exists only in the beginning when the rates are low and breaks down later when the dissolution rates remain finite.

To illustrate this mechanism, we have explored the following scenario. We have inserted a region where all fractures have initial apertures of $a_{0}=0.04 \mathrm{~cm}$ as indicated in Fig. 9a. Figure 9b depicts the evolution after 1200 years. The right-hand side column shows the evolution of the corresponding scenario without the widened region (standard scenario, Fig. 4). It is clearly seen that the zone of widened fractures attracts flow. The mixing zone is pushed upwards and the conduits of the cave system are located in this zone of wide fractures. It should be stressed at that point that regions with doubling of the initial aperture widths are sufficient to change the patterns of the cave systems drastically. Average initial widening of aperture widths is about $10^{-4} \mathrm{~cm} \mathrm{yr}^{-1}$ in all scenarios discussed in this work. Accordingly, only the very early state (200 years) of cave evolution is sufficient to create regions of doubled aperture widths that determine the future evolution of the cave system.

\section{Standard scenario with input of aggressive water}

So far we have assumed that the upwelling water is saturated with respect to calcite. If, however, the deep water on its way upwards does not pass any limestone formation, it will be undersaturated with respect to calcite. In the extreme case, its calcium concentration is zero. We have modelled this extreme case for the conditions $q=0.05 \mathrm{~cm}^{3} \mathrm{~s}^{-1}$ node ${ }^{-1}$ corresponding to $800 \mathrm{~mm} \mathrm{yr}^{-1}, Q=5 \mathrm{~cm}^{3} \mathrm{~s}^{-1}$ node $^{-1}, c_{\text {in }} / c_{\text {eq }}=$ 1 and $p_{\mathrm{CO}_{2}}=0.05 \mathrm{~atm}$ at the top $c_{\mathrm{in}} / c_{\mathrm{eq}}=0$ and $p_{\mathrm{CO}_{2}}=$ 

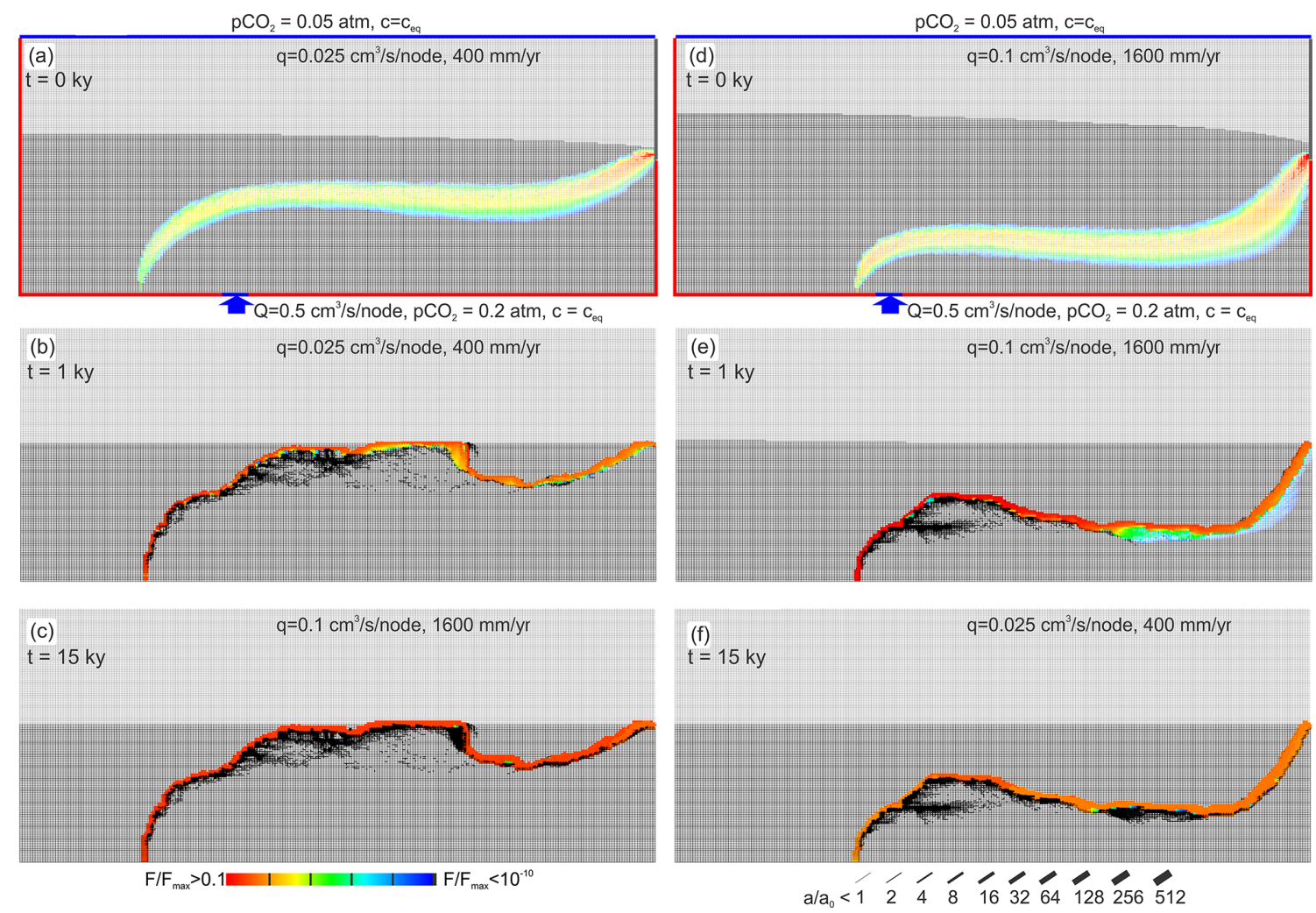

Figure 8. Temporal evolutions when meteoric recharge changes in time. (a-c) Initial input is $400 \mathrm{~mm} \mathrm{yr}^{-1}$ and stays constant for 10000 years, and then it switches to $1600 \mathrm{~mm} \mathrm{yr}^{-1}$ constant in time. (d-f) Initial input is $1600 \mathrm{~mm} \mathrm{yr}^{-1}$ and stays constant for 10000 years, and then it switches to $400 \mathrm{~mm} \mathrm{yr}^{-1}$ constant in time.

$1 \mathrm{~atm}$ at the bottom. The temporal evolution is shown in Fig. 10.

The flow domain of the water from below extends close to the water table. There MC is active as indicated by the red fringe. Due to the high hydraulic conductivity created by the aggressive water from below, the water divide drops to the highly conductive region, where further dissolution remains active.

In the initial state (Fig. 10a) two regions of dissolution are seen. The upwelling water is highly aggressive and creates a region (red) of high dissolution rates in the input region. More distant from the input this water approaches saturation, as one can see from the change in colour from red to blue. Due to the high input rate of the upwelling water, the water table is initially higher than in the standard scenario.

At the water divide between the flow domains the upwelling water is mixed with the meteoric water from the surface and gains renewed aggressiveness by MC, as can be seen from the red fringe in the mixing zone. The mixing zone is initially above the base level. Due to increasing hydraulic conductivity the mixing zone drops as karstification proceeds, leaving behind the widened inactive regions in the vadose and phreatic zones (Fig. 10b). After 1000 years (Fig. 10c) the region of dissolution has dropped to the base level. The mixing zone is limited to the outflow region. Dissolution is active only in the region at the bottom of the aquifer where inflowing water from below is guided due to the high conductivity that has been created there. At the end of its horizontal part the water rises, still maintaining its dissolution power. The flow domain of the water from below is restricted to the region of highly widened fractures. In the black region of the aquifer dissolution has stopped, leaving a complex pattern of widened fractures. This structure of the aquifer is stable in time, as can be seen from the panel at 40000 years (Fig. 10d). In the red region fractures widen continuously, creating complex caves. The aperture widths of the horizontal fractures along vertical transects as indicated in Fig. 10a are shown in Fig. 11.

In order to find the influence of flow rate, $Q$, of the upwelling water, we have reduced $Q$ from 5 to $0.05 \mathrm{~cm}^{3} \mathrm{~s}^{-1}$ node ${ }^{-1}$ and have left everything else as in Fig. 10. The result is shown in Fig. 12. Because of the reduced input, $Q$, the region of high dissolution rates (red) is much smaller and the mixing zone at a lower position compared to Fig. 10. After 200 years (Fig. 12b) dissolution is active in both the plume of upwelling water and in the mixing zone. At 800 years (Fig. 12c) flow is mainly along the channel that has evolved along the mixing zone, and only there 

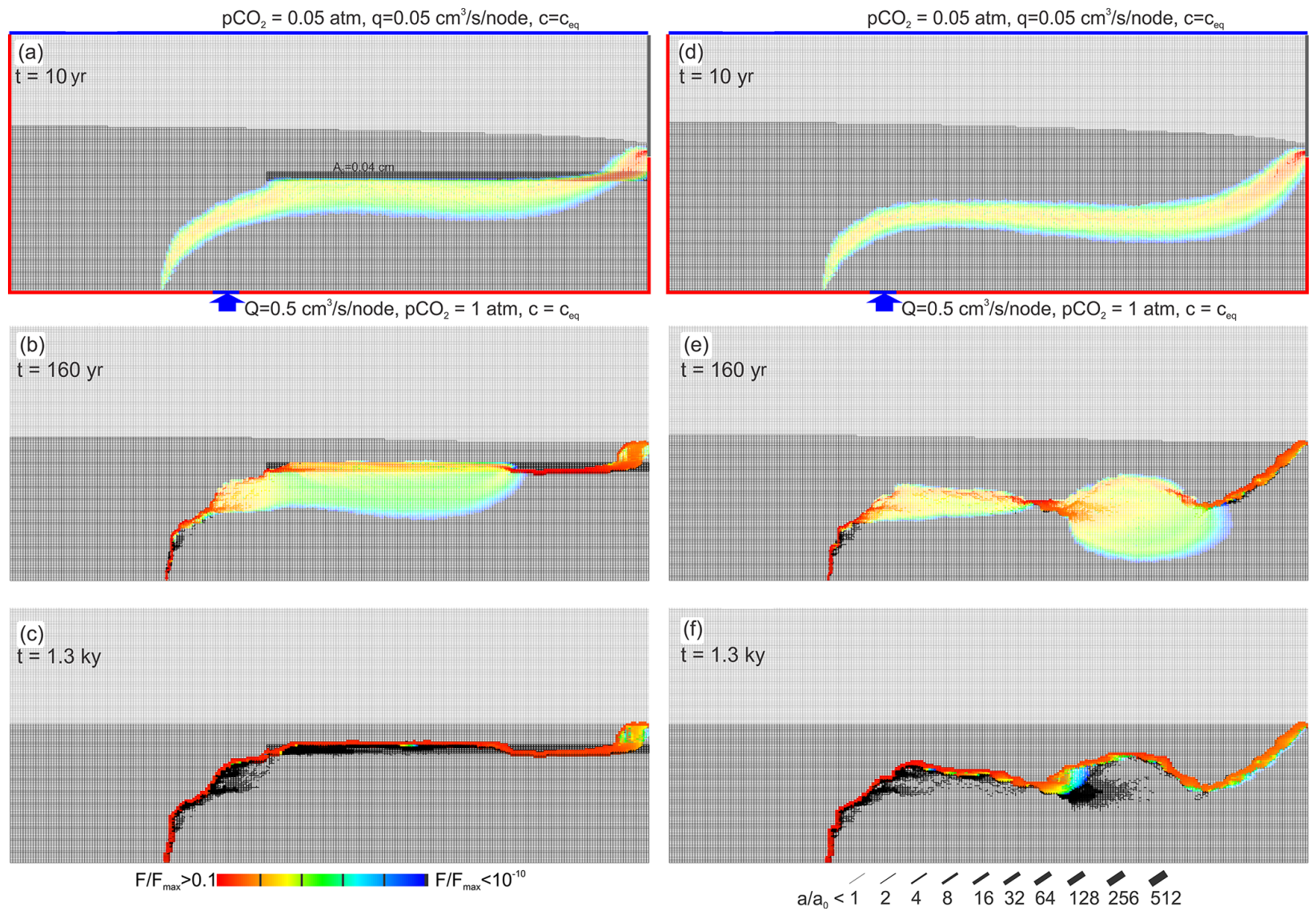

Figure 9. Evolution of the standard scenario with region fractures with larger initial aperture $a_{0}=0.04$ by black region (a-c) compared to the evolution of the standard scenario on the right-hand side (d-f). The region of enlarged fractures dominates the evolution.
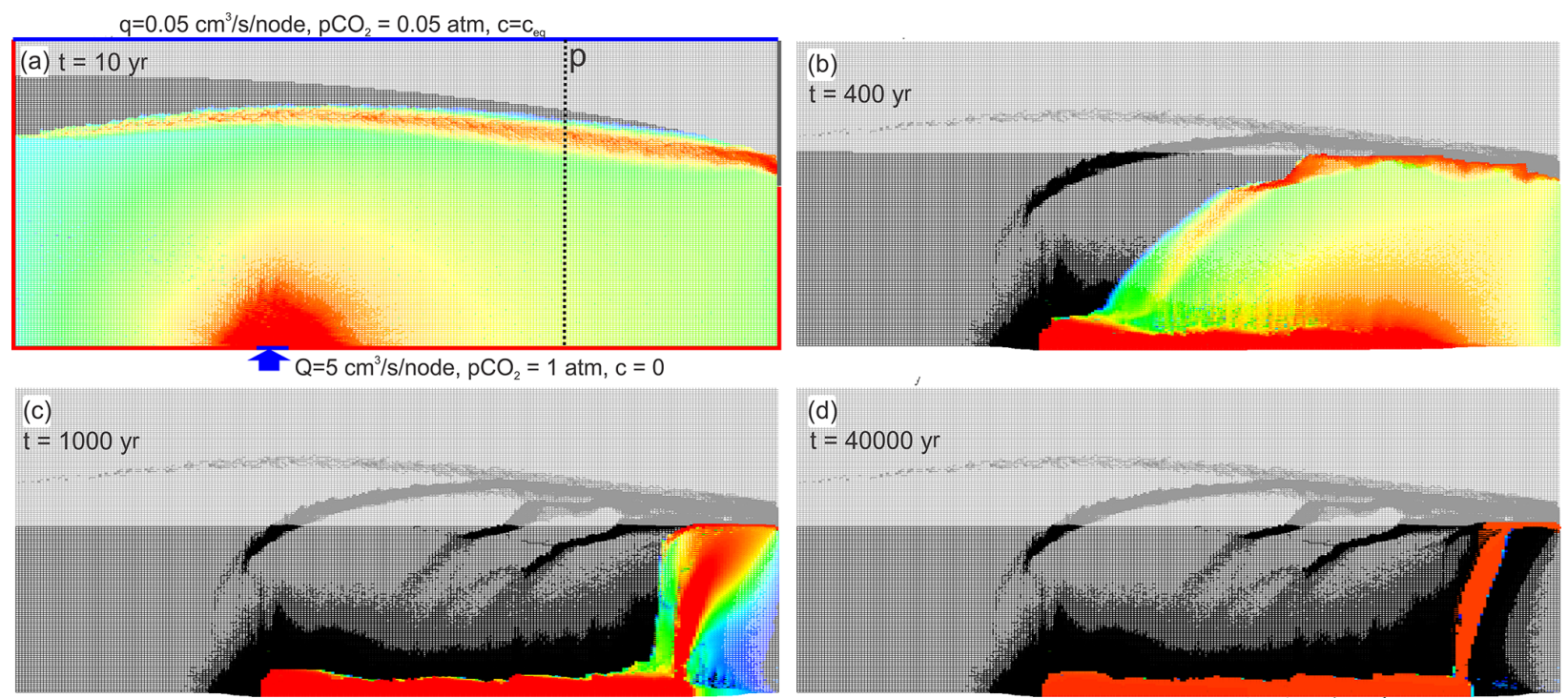

$\mathrm{F} / \mathrm{F}_{\max }>0.1 \quad \mathrm{I} \quad \mathrm{I} \quad \mathrm{I} / \mathrm{F} / \mathrm{F}_{\max }<10^{-10}$

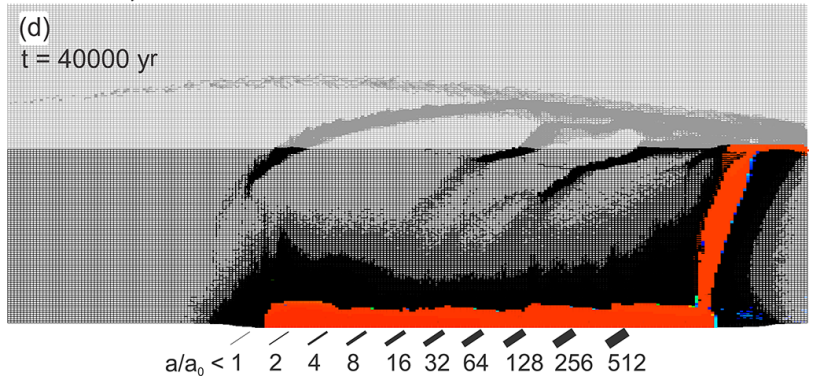

Figure 10. Standard scenario with upwelling water undersaturated with respect to calcite, $c_{\text {in }}=0$, and input raised to $5 \mathrm{~cm}^{3} \mathrm{~s}^{-1}$. The red region indicates high rates of fracture widening. 


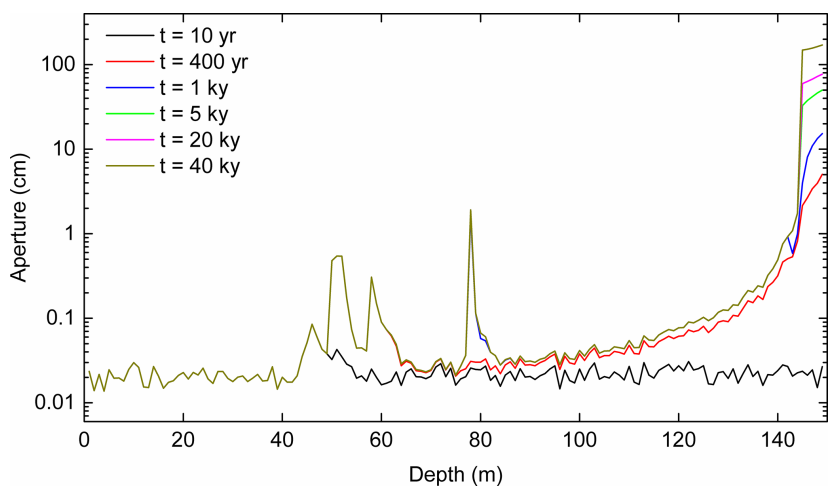

Figure 11. Aperture widths of horizontal fractures along a vertical profile at the position marked by dashed line (p) in Fig. 10a. Note that in the late evolution widening of fractures is restricted to the fractures at base level.

do the fractures widen. This pattern remains stable, as can be visualized after 10000 years (Fig. 12d).

To complete our understanding of dissolution patterns, we have addressed the question of what happens when both the meteoric surface water and the upwelling water from below are undersaturated with respect to calcite. To study this systematically, we compare the results of three scenarios.

a. The meteoric water that enters the water table is undersaturated with concentration $c_{A}=0.9 c_{\mathrm{eq}}^{A}, p_{\mathrm{CO}_{2}}=$ $0.05 \mathrm{~atm}$, and $q=0.05 \mathrm{~cm}^{3}$ node $^{-1} \mathrm{~s}^{-1}$. The water from below is undersaturated as well, with $c_{B}=0.9 c_{\mathrm{eq}}^{B}$, $p_{\mathrm{CO}_{2}}=1 \mathrm{~atm}$, and $q=0.5 \mathrm{~cm}^{3}$ node $^{-1} \mathrm{~s}^{-1}$.

b. The meteoric water is undersaturated, $c_{A}=0.9 c_{\mathrm{eq}}^{A}$, and the upwelling water is saturated, $c_{B}=c_{\mathrm{eq}}^{B}$.

c. Both the surface water and the upwelling water are saturated with respect to calcite. This case is already illustrated in Fig. 4, right-hand side panels, and discussed there.

All other conditions in scenario A and scenario B are equal as in Fig. 4.

The temporal evolution of scenario $\mathrm{A}$ is illustrated in Fig. 13. In the beginning (panel a) we observe three regions of dissolution, the first at the water table where the aggressive surface water enters (yellow fringe). In the zone where rainwater mixes with the water from below, renewed aggressiveness arises by MC (yellow region). Finally, a plume extends from the input region of aggressive water from below (yellow). After 120 years (panel b) enhanced dissolution is observed in the bottom region, where water from below enters and in the fringe of mixing (red). After 1300 years (panel c) dissolution at the bottom is restricted to the input nodes. Mixing with high dissolution rates becomes restricted to a narrow band. Below this an extended zone of reduced rates (blue) is seen. Dissolution at the water table is similar to that of past times before. This pattern remains stable (panels d and e) until 30000 years and thereafter. Most of the flow is focused on the water table cave and the cave system below. The black regions below show fractures with increased aperture widths invaded by saturated solutions. Therefore, dissolution in this region is absent.

Figure 14 shows the evolution of scenario B (saturated upwelling water, undersaturated meteoric input). In the beginning, two regions of dissolution are seen. The undersaturated rainwater establishes a region of fracture widening at the water table. Mixing of rainwater that has become almost saturated on its way down with the upwelling water creates a fringe of mixing corrosion. There a cave system is evolving. At the same time, the meteoric water widens the fractures at the water table, creating a zone of high hydraulic conductivity, which in time drains most of the meteoric water to the output on the right. Therefore, the meteoric water no longer intrudes downwards, and the mixing corrosion is no longer active. The entire region below is invaded by the upwelling water that is saturated with respect to calcite (black region), and further dissolution there stops. The water table cave however continues to grow.

Figure $15 \mathrm{a}-\mathrm{c}$ illustrate the three final evolution states of scenarios A, B, and C, presented in Figs. 13, 14, and 4. Panel a depicts the situation when both waters are undersaturated. Here due to the aggressive water from below dissolution rates along the mixture fringe are enhanced, and flow from below occupies this region and that below it. Panel $\mathrm{b}$ depicts the final state when the meteoric water is aggressive only, as in Fig. 11. By the increasing hydraulic conductivity at the water table most of the flow of meteoric water is directed along this region. Mixing with the water from below is also restricted to this region, where the water creates high dissolution rates.

In panel a, both the meteoric water and the water from below are saturated with respect to calcite as in Fig. 4. Dissolution results from MC and lasts during the entire time of evolution. Figure $14 \mathrm{~d}-\mathrm{f}$ illustrate the aperture widths of the horizontal fractures along the vertical transect as indicated on the corresponding left-hand side.

\section{Mixing corrosion-fringe instability in the mixing zone}

In all scenarios with pure MC discussed in this work we observe a common behaviour during the early time of cave evolution. This is shown in Fig. 16. The left-hand side panels repeat the evolution already shown for the standard scenario in Fig. 4. In the beginning when dissolution has not yet been active, a wide fringe of mixed waters extends to both sides of the water divide between the two flow domains. At the output where flow is constricted to a narrow region, the fringe of mixing is also narrow, and one-to-one mixing occurs in its middle, creating maximal widening of fractures, as can be read from the red fractures. Therefore, flow is focused 
$\mathrm{q}=0.05 \mathrm{~cm}^{3} / \mathrm{s} /$ node $, \mathrm{pCO}_{2}=0.05 \mathrm{~atm}, \mathrm{c}=\mathrm{c}$
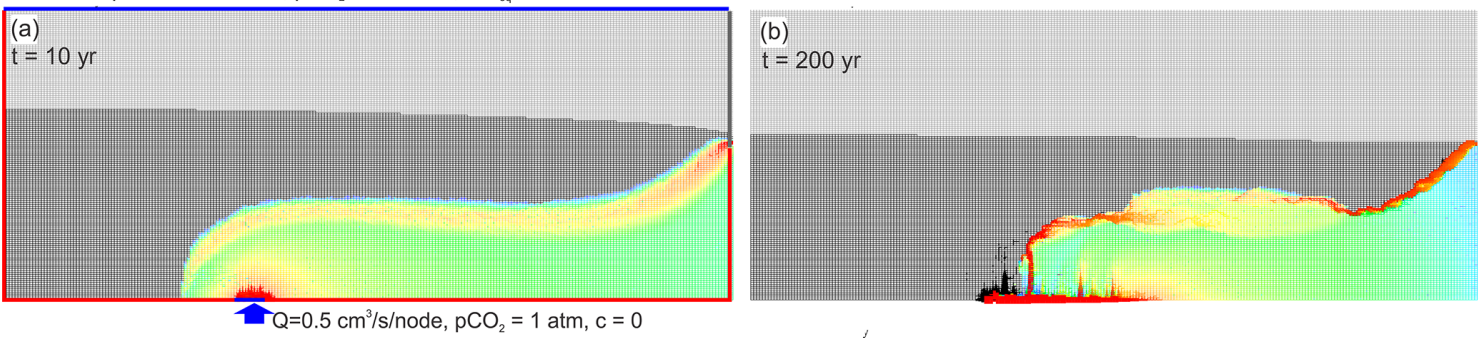

(c) $\mathrm{t}=800 \mathrm{yr}$

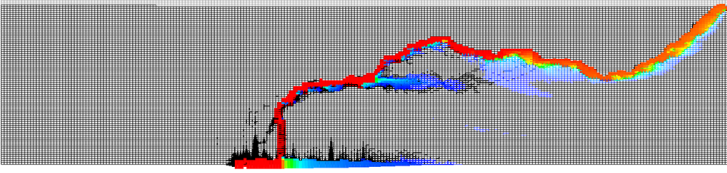

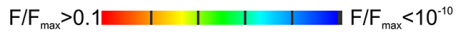

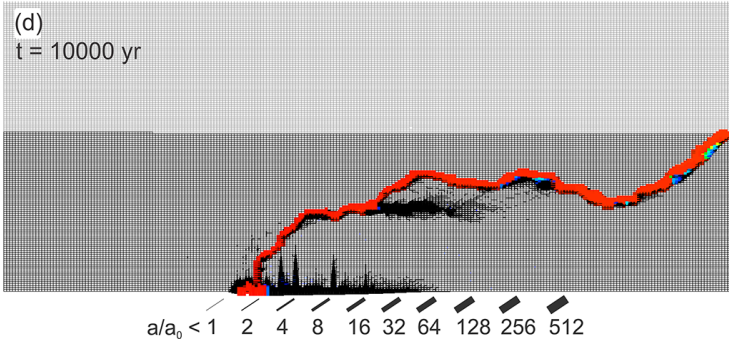

Figure 12. Standard scenario but upwelling water is undersaturated with respect to calcite, $c_{\text {in }}=0$. The red region indicates high rates of fracture widening. The highly aggressive water is channeled to the mixing zone at the water divide.
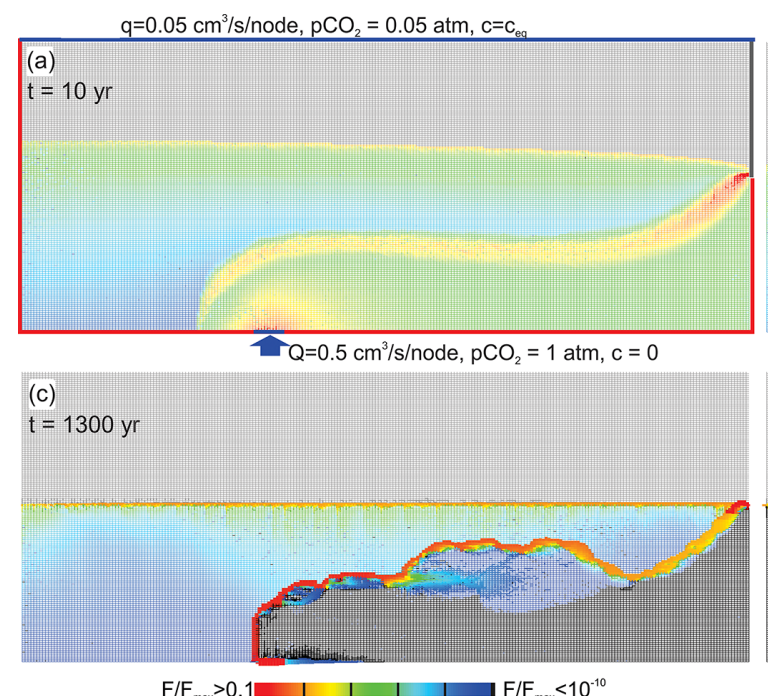

Figure 13. Temporal evolution of scenario A. See text.

and the cave develops in this narrow region propagating upstream. This is a common feature in all scenarios where dissolution in a mixing fringe is of relevance.

After a short time the shape of the fringe is distorted (Fig. 16c). It is constricted to a narrow zone. In the middle of it dissolution rates are high, as seen by red fractures. Beyond this constriction, an extended region of mixing with low rates of widening extends until it is squeezed again because its flow is channeled into the cave that propagates upstream.

The first constriction arises by an instability caused by chance due to the heterogeneity of the fracture aperture widths. Somewhere in the mixing zone, dissolution rates are maximal compared to the neighbouring ones (Fig. 16b). They
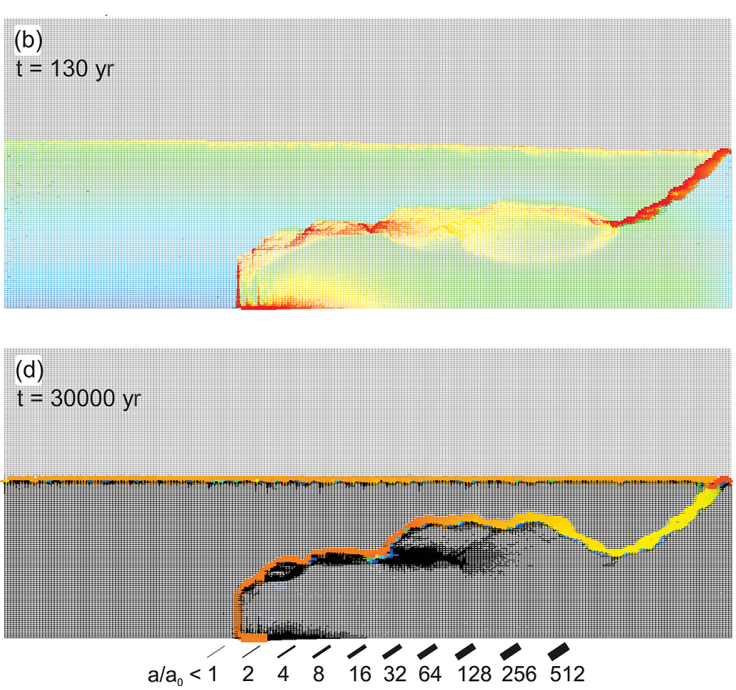

create a narrow region that attracts flow, increasing further favourable mixing. This causes a feedback loop as already described. At the end of this region, flow is dispersed and the extended zone of mixing is created.

To show that it is the heterogeneity of the fracture widths that causes the instability, we have investigated what happens (not shown here) when all fractures have equal uniform aperture widths of $0.02 \mathrm{~cm}$. Here during the time ranges explored in Fig. 15 no instability occurred. This gives a warning of the reliability of digital models that are high idealizations of nature.

To give further support to our interpretation in the righthand side panels (Fig. 16d-f), we show the evolution of a 
$\mathrm{q}=0.05 \mathrm{~cm}^{3} / \mathrm{s} /$ node $, \mathrm{pCO}_{2}=0.05 \mathrm{~atm}, \mathrm{c}=0.9 \mathrm{c}_{\mathrm{eq}}$

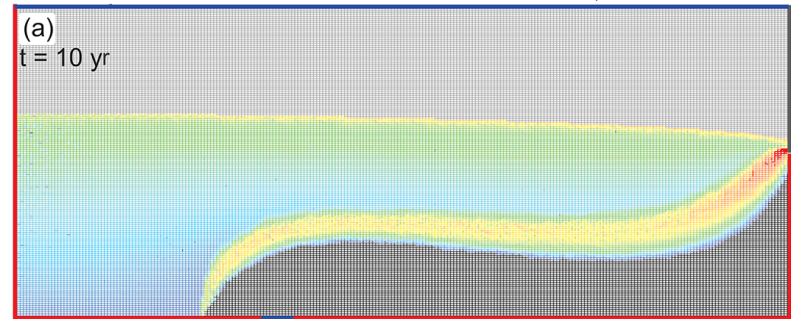

$\mathrm{Q}=0.5 \mathrm{~cm}^{3} / \mathrm{s} /$ node, $\mathrm{pCO}_{2}=1 \mathrm{~atm}, \mathrm{c}=\mathrm{c}_{\mathrm{eq}}$

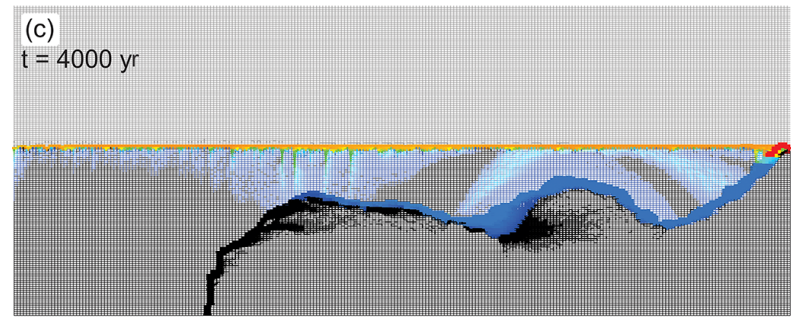

$\mathrm{F} / \mathrm{F}_{\max }>0.1 \quad \mathrm{I} \quad \mathrm{I} \quad \mathrm{I} \quad \mathrm{F} / \mathrm{F}_{\max }<10^{-10}$

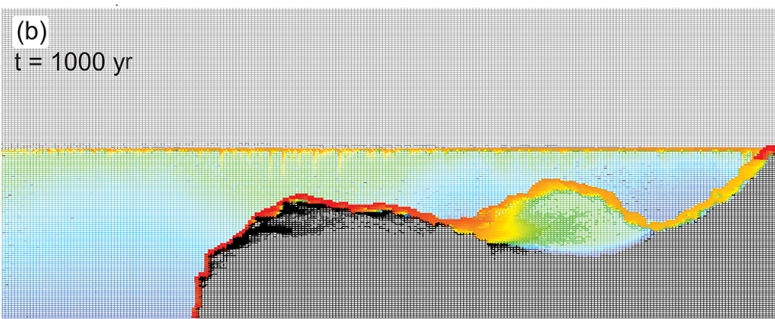

(d)

$t=20000 y r$

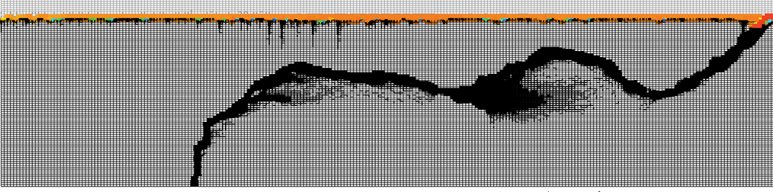

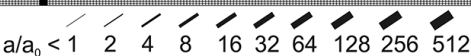

Figure 14. Temporal evolution of scenario B. See text.
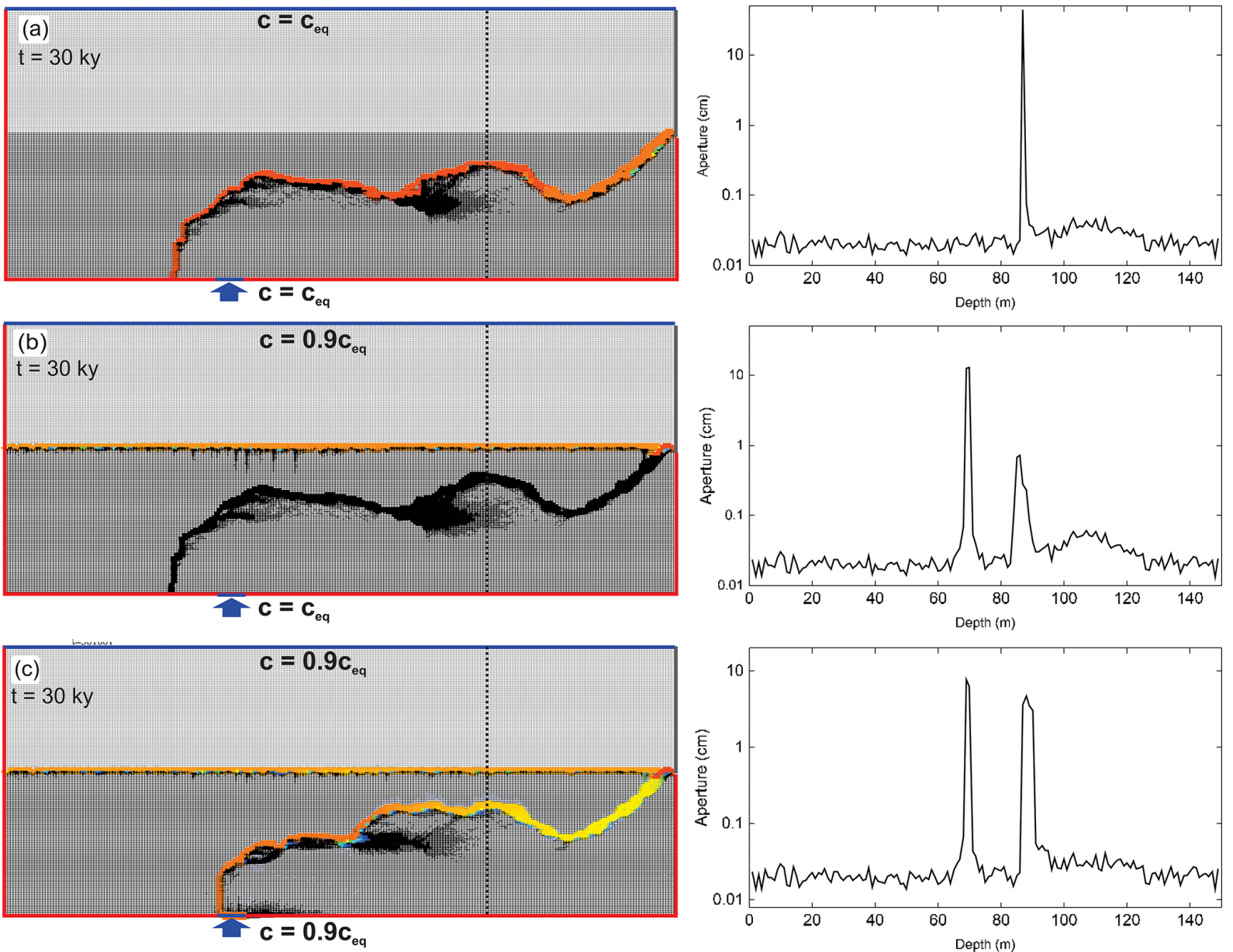

Figure 15. Final evolution states of scenario A, Fig. 13, scenario B, Fig. 14, and standard scenario C, Fig. 4. Panels on the right show widths of horizontal fractures along profile lines shown in $(\mathbf{a}-\mathbf{c})$. 

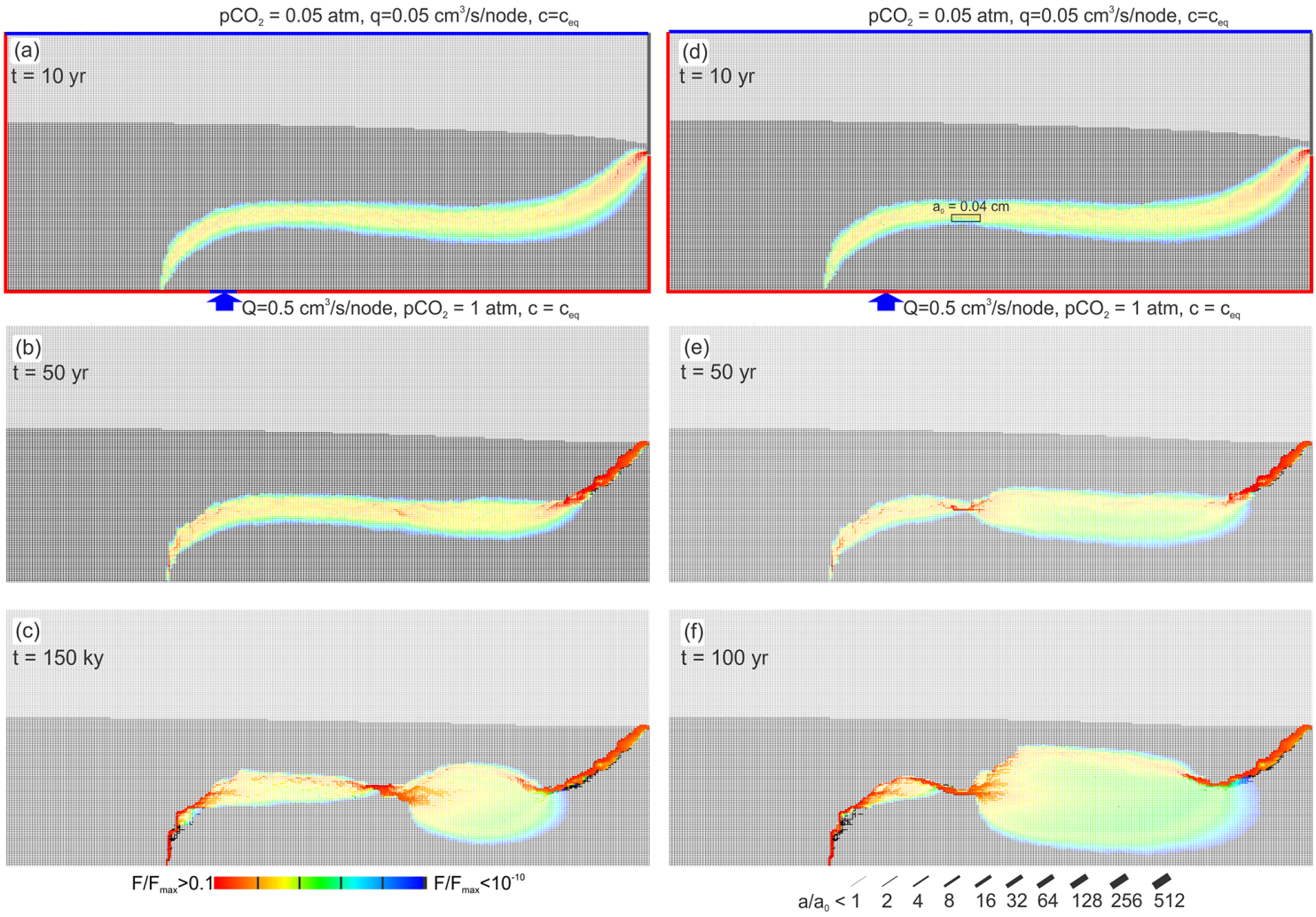

Figure 16. Evolution of mixing zone instability and constriction. (a-c) Standard case (see Fig. 4); (d-f): standard case, where instability was triggered by assigning the initial aperture $a_{0}=0.04 \mathrm{~cm}$ to a set of four horizontal fractures, marked by rectangle in (d).

scenario where a zone of wider fractures $(0.04 \mathrm{~cm})$ has been introduced as indicated by the black rectangle. In this case the constriction occurs exactly in this region.

One would expect that such constrictions should occur again in the downstream region. This, however, is prevented by focusing on the narrow output region. Therefore, we have extended the modelling domain from 500 to $1400 \mathrm{~m}$ in the horizontal direction. The result is shown in Fig. 17. In the beginning, the fringe of mixing extends along the entire length of the domain. However, in the further evolution a series of constrictions arise, as expected.

\section{Impact of boundary conditions}

In all our scenarios so far outflow was focused on the seepage face. To explore the impact of boundary conditions on the evolution of karst by MC, we have replaced the noflow boundary below the seepage face with a constant head boundary with head zero. In nature, this could be a river or a lake located at the rim of the rock massif that hosts the cave system.

The result is illustrated in Fig. 18. As in all scenarios that we have reported, a mixing fringe is present in the beginning. It shows two constrictions downstream due to the $\mathrm{MC}$ instability. From there a wide mixing zone extends with large widening of fractures at its upper rim. These regions of high dissolution rates determine the location of the cave. This shows that the MC-fringe instability is a unique property of the MC fringe independent of the specific output boundary conditions.

\section{Pattern of flow}

To further illustrate the origin of the mixing zone instability, we have investigated the flow pattern and its relation to dispersive mixing. Figure 19 presents the standard scenario with arrows presenting the average direction and flow rate in $5 \times 5$ subdomains. The length of the arrow presents the flow rate in a subdomain normalized to the flow rate in the subdomain with maximal flow. This way flow lines can be envisaged easily.

Panel a depicts the pattern of flow rates at the onset of dissolution. In the upper flow domain resulting from meteoric input, all arrows point downwards and all flow lines that can be envisaged from these arrows are first directed downwards; then, they bend and become almost parallel to the upper fringe of the mixing zone until they are directed to the outflow. There the flow lines are squeezed into a narrow band, and accordingly their amount increases, as can be seen by the long arrows. The flow lines inside the mixing zone 

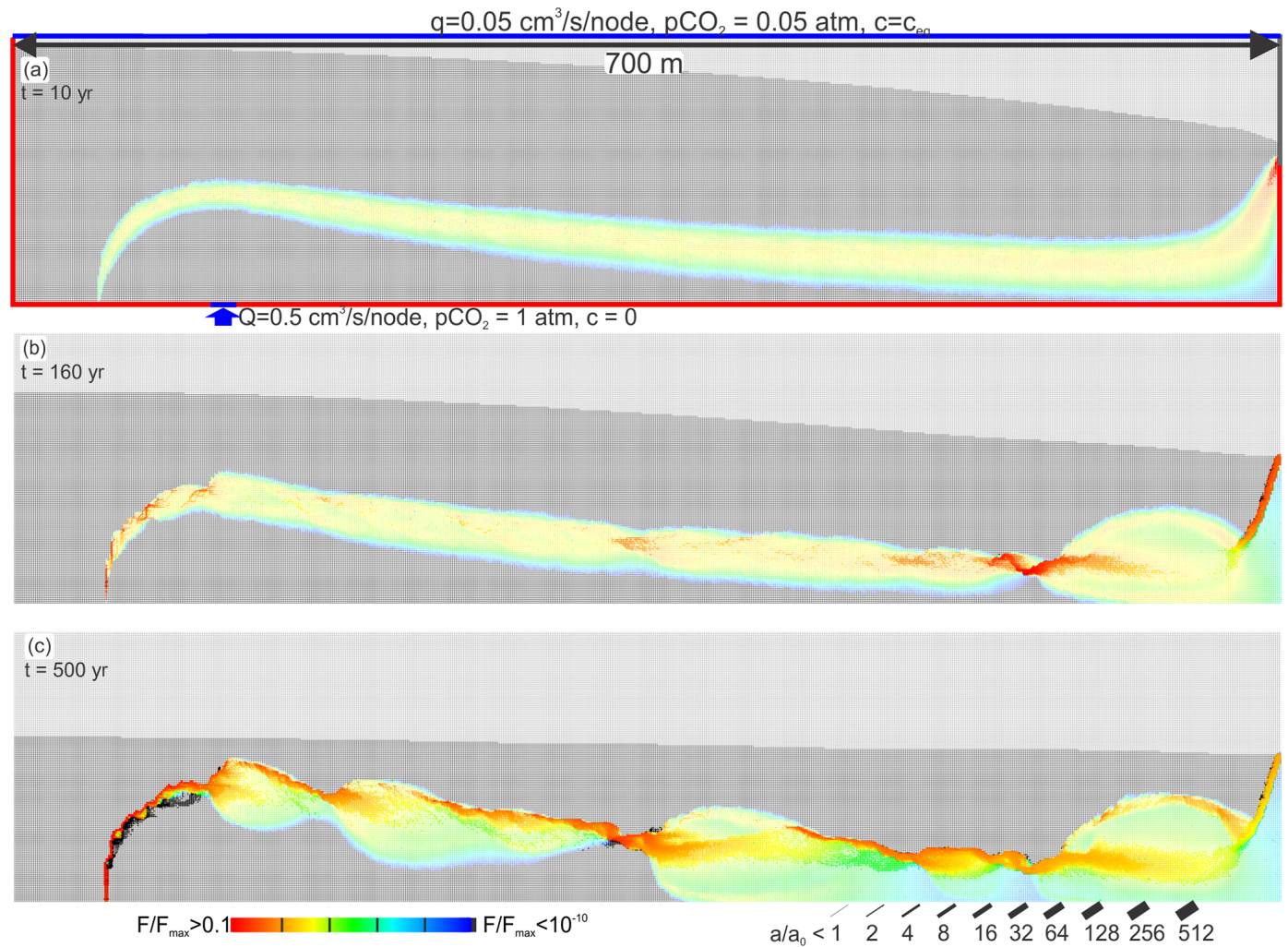

Figure 17. Standard scenario with horizontal extension of the modelling domain from 500 to $1400 \mathrm{~m}$. Several constrictions occur downstream.

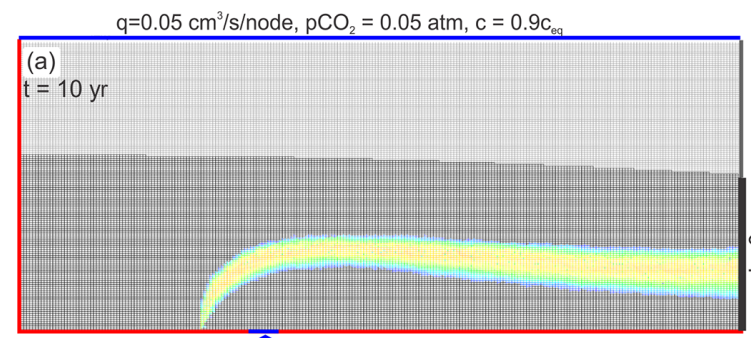

$\mathrm{Q}=0.5 \mathrm{~cm}^{3} / \mathrm{s} /$ node, $\mathrm{pCO}_{2}=1 \mathrm{~atm}, \mathrm{c}=\mathrm{c}_{\mathrm{ed}}$

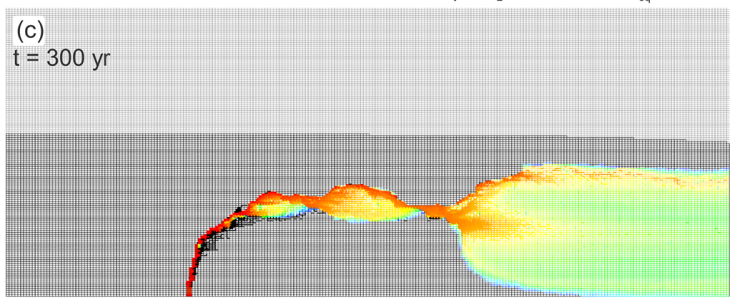

$F / F_{\max }>0.1 \quad 1 \quad 1 \quad 1 \quad \mid \quad F / F_{\max }<10^{-10}$
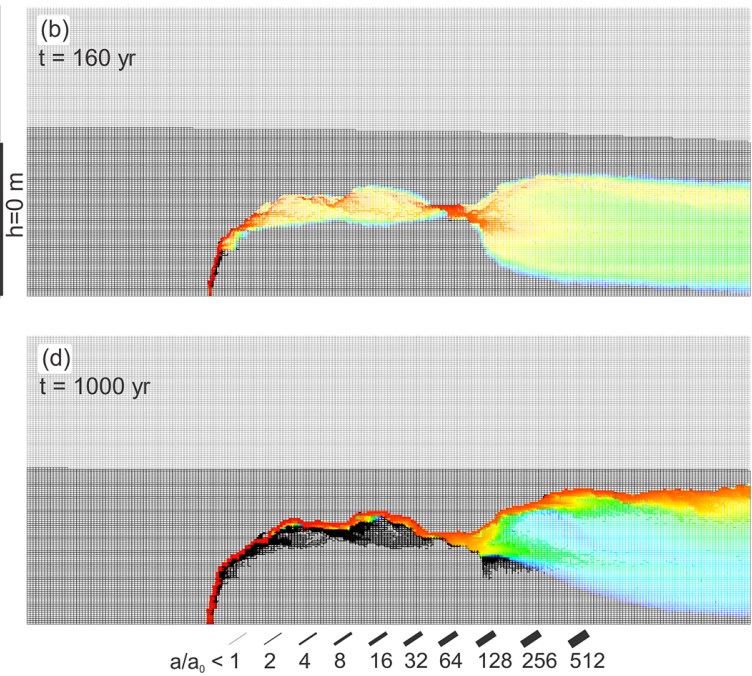

Figure 18. Change in boundary conditions on the outflow to constant head conditions.

and those touching it at its rims are almost parallel to each other. The flow lines in the lower flow domain originating from the hypogenic input rise from the input region and then bend and become parallel to the lower fringe of the mixing zone. Finally, they are directed towards the output.
Mixing between the surface water and the hypogenic water is possible only where the flow rate vectors are located in the mixing zone or close to the water divide. One-by-one mixing and, accordingly, widening of fractures are enhanced in all regions in the mixing zone where the flow vectors have vertical components. These regions are indicated by shaded 


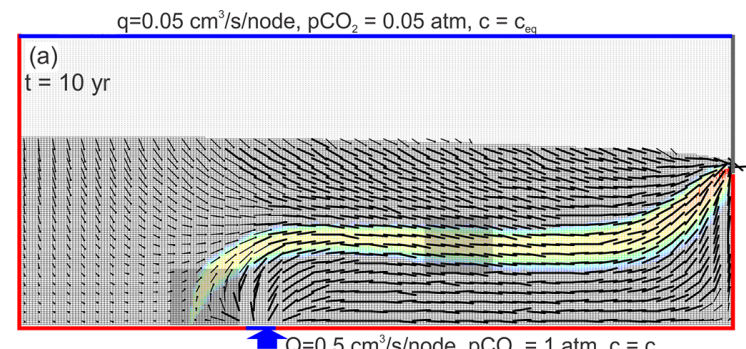

$\mathrm{Q}=0.5 \mathrm{~cm}^{3} / \mathrm{s} /$ node, $\mathrm{pCO}_{2}=1 \mathrm{~atm}, \mathrm{c}=\mathrm{C}_{\text {eq }}$
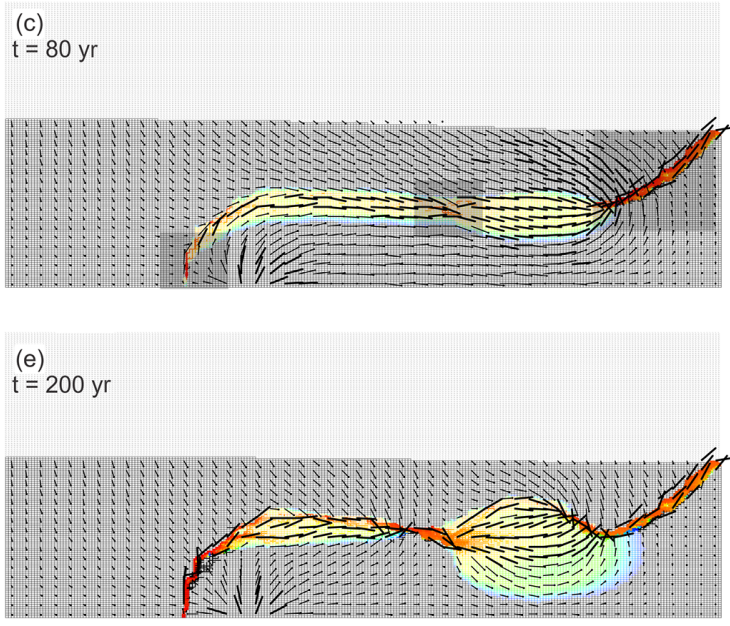

$\mathrm{F} / \mathrm{F}_{\max }>0.1 \quad \mathrm{I} \quad \mathrm{I} / \mathrm{F} / \mathrm{F}_{\max }<10^{-10}$

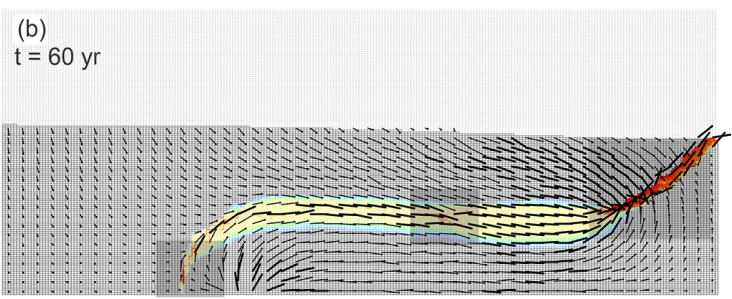

(d) $\mathrm{t}=120 \mathrm{yr}$

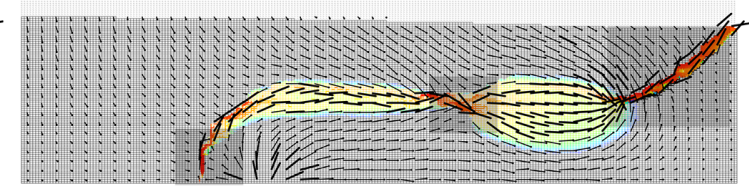

$t=450 y r$

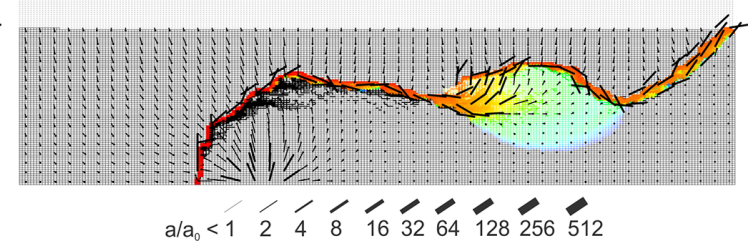

Figure 19. Patterns of flow lines for the standard scenario.

rectangles in panels a-d. From these one understands why dissolution rates are high at the output and in the region.

\section{Discussion}

By the action of mixing corrosion, hypogenic caves evolve in a large variety of geological settings. We have chosen our specific setup of an unconfined aquifer that is similar to the geology of the caves in the Black Hills (Palmer, 2017) and also bears a great similarity to that of hypogenic settings in the Guadalupe Mountains, New Mexico, USA, e.g. Carlsbad Caverns, Lechuguilla Cave sculptured by SAS (Palmer, 2006).

In SAS, oxygen-rich waters from the surface mix with water rising from the depth that is saturated with respect to calcite and contains $\mathrm{H}_{2} \mathrm{~S}$. This way, similarly to in CAS, a mixing zone is created. There by bacterial aid $\mathrm{H}_{2} \mathrm{~S}$ is oxidized to $\mathrm{H}_{2} \mathrm{SO}_{4}$ that dissolves limestone readily, thereby producing $\mathrm{CO}_{2}$ as a further agent for dissolution. This mixing process is close to that in our hypothetical CAS setup. However, there is not sufficient knowledge on details of these complex processes, especially about the location of bacteria in the fractures or their junctions and the kinetics of bacterial oxidation. Therefore, modelling of SAS is not possible. Nevertheless, the basic processes of cave formation should be similar to those of CAS. Therefore, albeit with care, our results may serve to interpret SAS cave systems.

In this work, we have focused on a specific setting that offers new speleological mechanisms in an unconfined aquifer open to meteoric waters from the surface as they have been reported in the speleogenesis of the caves in the Black Hills, South Dakota, USA, and the Guadalupe Mountains, New Mexico, USA. Such a model must be kept idealized and simple to reveal the basic mechanisms acting. It cannot explore the evolution of real cave systems because these may have undergone multiple phases of speleogenesis governed by different geological settings and hydrogeological conditions. Such changing conditions imprint the geological history onto the cave evolution and would add a complexity that masks the basic contributions to further speleogenesis. The focus of this work is to construct a plausible hydrogeological setting to explore how and where fractures are enlarged by dissolution. This is a tool that reveals insights which cannot be found otherwise. To our knowledge, no modelling of speleogenesis has ever been attempted to understand detailed patterns of real cave systems. Most modelling works can be regarded as building blocks of a better understanding of processes active in early karstification.

Of course, other scenarios can be envisaged. In our setting the aquifer initially may have been confined by impermeable strata on top of it. Then two possibilities exist. In the first 


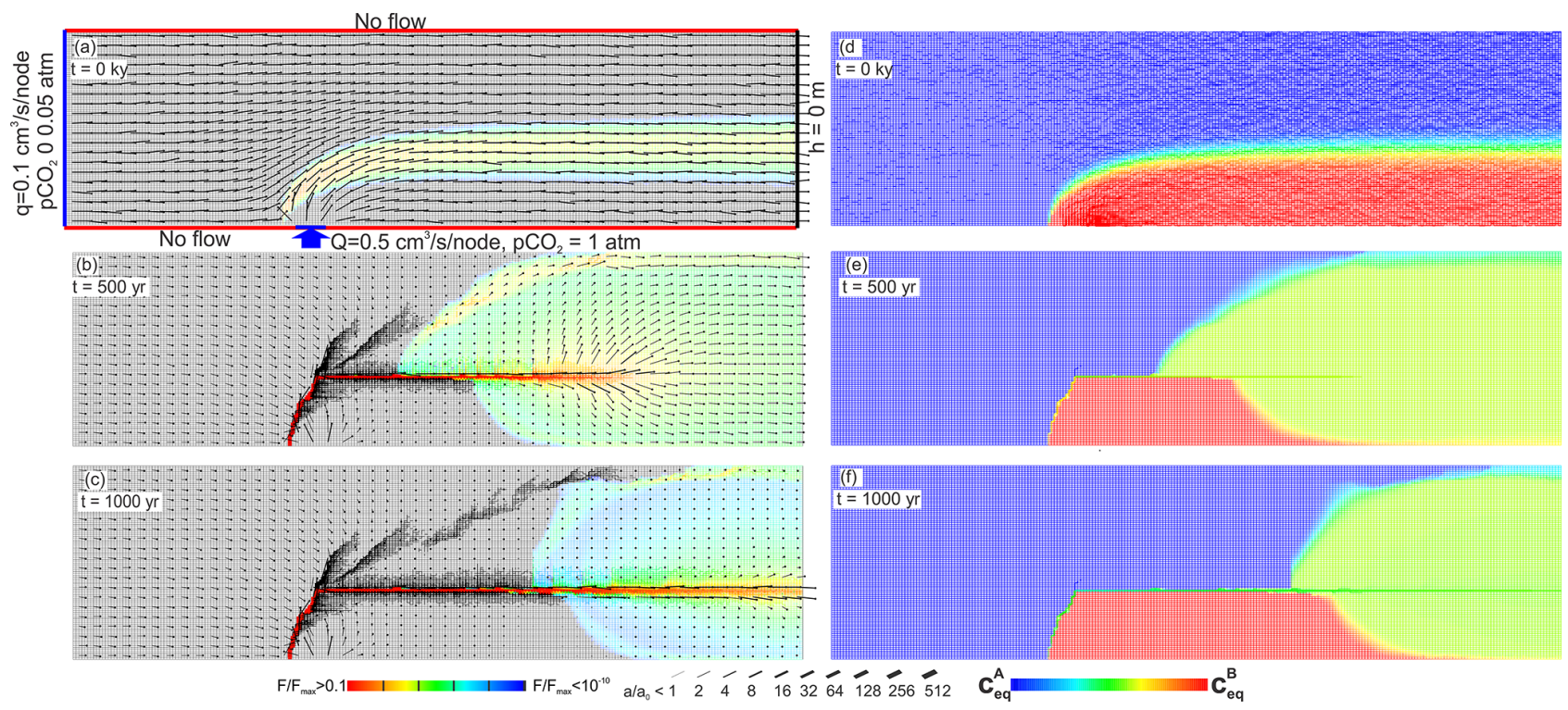

Figure 20. Evolution of the confined aquifer. The left panels represent fracture aperture widths (bar code below) and widening of the fractures in $\mathrm{cm} \mathrm{yr}^{-1}$ (colour code below). Black regions do not experience widening by dissolution. The right panels represent flow rates (bar code $Q / Q_{\max }$, where $Q_{\max }$ is the maximal flow occurring in the net) and the values of $c_{\text {eq }}$ (colour code) of the water. Blue regions contain phreatic water from the input on the left-hand side of the modelling domain. Red regions are filled with upwelling water from below.

the waters from below, saturated with respect to calcite, are the only input of water. Then the aquifer is filled with that saturated water and karstification is not possible. It will start when the aquifer is unroofed by uplift and erosion. This is equivalent to our model. Here a limestone plateau is bordered by two valleys, and due to the confining cover the aquifer is filled with the upwelling water from depth, avoiding dissolution of limestone until the aquifer is unroofed.

In the second possibility the aquifer receives water from some distant input upstream from the modelled region. Then karstification by mixing corrosion will imprint patterns of porosity and cave conduits that are inherited when the aquifer becomes unconfined. Although study of such a setup is beyond the scope of this work, we give an example. We chose a setup that is similar to the one presented by Gabrovšek and Dreybrodt (2010).

Here we assume that water from a distant input flows into our aquifer that is now confined by impermeable strata on top of it. This is modelled by changing the boundary conditions of the standard case (see Fig. 4) to a constant input condition of saturated water with $p_{\mathrm{CO}_{2}}=0.05 \mathrm{~atm}$ the left-hand side of the modelling domain and constant head on its right-hand side.

Figure 20 illustrates the result at three steps of the evolution. At the onset, two flow domains (red and blue) separated by a mixing fringe are clearly visible. After 500 years, a channel has developed from the input upwards and then horizontally. During its propagation, the solution from the channel is injected into the adjacent network, where it mixes with the regional flow. Dissolution in mixing zones imprints regions of increased permeability. At 500 years we see regions of high permeability and active dissolution in the mixing zone that is restricted to the border of the two flow domains (red and blue in Fig. 20d-f). Such a pattern then continues as the channel evolves towards the output boundary. This scenario is almost an upside-down image of the model presented by Gabrovšek and Dreybrodt (2010), where the saturated solution from the surface mixes with the left-right regional flow.

To account for the fact that evolution of most aquifers started in confined settings, one could use an end-member of such a model as an initial domain for the unconfined setting presented in this work. This could be an interesting topic for the future but is beyond the scope of this work that might be considered a first step in this direction.

Generally, one could argue that our setting is too idealistic. It is likely that a system of larger fractures intersects the idealized aquifer in our setting. Figure 21 shows a situation where we have inserted a coarse grid of prominent fractures with an aperture width of $0.05 \mathrm{~cm}$. The deep flow is injected into a single prominent fracture as shown in Fig. 21. Due to this injection, the mixing zone forms similarly to in the standard case (Fig. 4). The middle prominent fracture is located in this mixing zone and attracts flow, as can be seen after 50 years by the red colour indicating high dissolution rates. Then flow focuses on the more permeable horizon of the prominent fracture and the mixing fringe is restricted to this region. However, as seen in Fig. 21b, mixing zone constrictions also arise along the prominent fractures. The water from these constrictions is injected into the network, caus- 

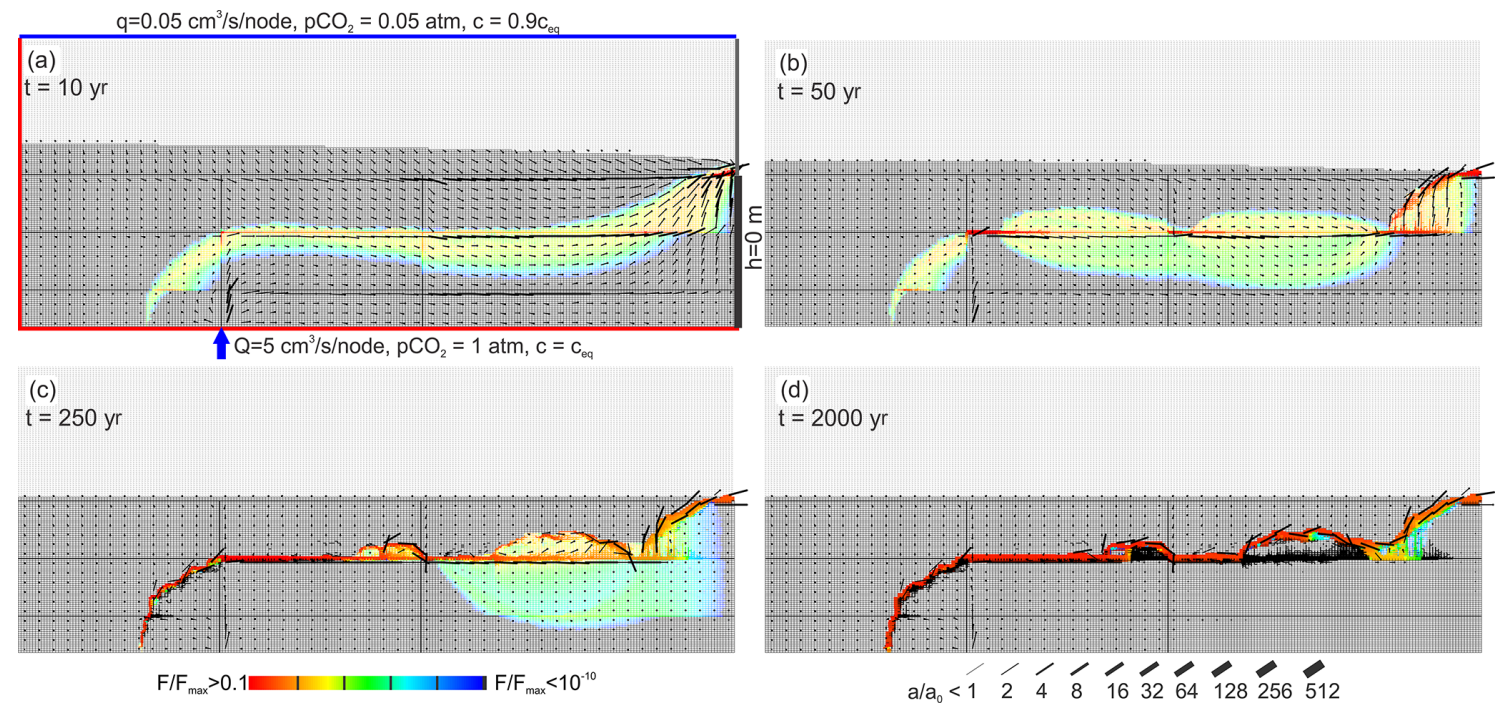

Figure 21. Regular network of prominent fractures of aperture width $A_{0}=0.05 \mathrm{~cm}$ embedded in the standard network. Input of deep water is introduced along a single prominent fracture. Everything else as in the standard scenario (Fig. 4).

ing additional growth as it mixes with the infiltrated water. This gives rise to growth of stable pathways within the fine fracture network that bypass the middle prominent fracture (Fig. 21c and d).

We do understand this behaviour in view of the insights we have gained from our idealistic setting. If we had explored the more complex setting from the beginning, insights revealed from the idealistic setting would have remained concealed. This is an example of the significance of idealistic simple models as building blocks to understand more complex situations.

\section{Conclusion}

We have proposed the first digital models of hypogenic carbonic acid speleogenesis (CAS) as suggested already by Palmer and Palmer (1989). They argued that where waters saturated with respect to calcite but with differing $\mathrm{Ca}$ concentration are mixed, mixing corrosion will become active as a cave-forming mechanism. Many geological settings can be considered where such conditions are true. In this work we explore by digital modelling a simple idealized setting. Meteoric water percolates into a limestone massif, attaining saturation with respect to calcite when it meets the water table. From below deep-seated water loaded with $\mathrm{CO}_{2}$ rises reaches saturation with respect to calcite and invades the limestone. In Darcy flow two flow domains are established that are separated by a water divide. There, due to dispersive diffusion, the different waters mix in a fringe surrounding the water divide and mixing corrosion sets in widening the aperture of the fractures. The water leaves the aquifer at a seepage face in most of our computer runs. The cave evolves first at the output and at the depth of the aquifer close to the input from below. Between these regions a wide fringe of smaller dissolution rates develops.

This fringe in its middle due to the heterogeneity of the fractures develops constrictions with increasing dissolution rates and attracts flow from both waters that mix there to reach maximal dissolution rates. Finally, a cave system bending up and down attracts all flow such that its pattern stays stable in time but with increasing widths of conduits.

Depending on the parameters of the computer runs such as dimensions of the aquifer, magnitude of water input, $q$, from below and the amount, $Q$, of meteoric precipitation as well as the ratio $Q / q$ that determines the position of the initial flow domains, a variety of cave patterns are obtained. We have modelled cases when the meteoric input varies in time and found that the early state of cave evolution determines its final pattern.

Our modelling results have some consequences for the definition of hypogenic karst. Both definitions, that by Palmer (2000) from the geochemical view as well as that by Klimchouk $(2007,2016)$ from a hydrological approach, state independence of hypogenic karstification on surface processes. In CAS as well as in SAS, however, surface processes do have a strong impact.

Code availability. The code is available on request from Franci Gabrovšek.

Data availability. No data sets were used in this article.

Author contributions. WD initiated the work and wrote the text. FG is the author of the model code. He performed the simulations 
and prepared the figures. The paper is based on the in-depth discussions of both authors.

Competing interests. The authors declare that they have no conflict of interest.

Financial support. The study was partially supported by the Slovenian Research Agency (research core funding no. P6-0119).

Review statement. This paper was edited by Insa Neuweiler and reviewed by Alexander Klimchouk and Steffen Birk.

\section{References}

Andre, B. and Rajaram, H.: Dissolution of limestone fractures by cooling waters: Early development of hypogene karst systems, Water Resour. Res., 41, W01015, https://doi.org/10.1029/2004WR003331, 2005.

Audra, P. and Palmer, A. N.: Research frontiers in speleogenesis. Dominant processes, hydrogeological conditions and resulting cave patterns, Acta Carsologica, 44, 315-348, https://doi.org/10.3986/ac.v44i3.1960, 2015.

Birk, S., Liedl, R., Sauter, M., and Teutsch, G.: Hydraulic boundary conditions as a controlling factor in karst genesis: A numerical modeling study on artesian conduit development in gypsum, Water Resour. Res., 39, 1004, https://doi.org/10.1029/2002WR001308, 2003.

Birk, S., Liedl, R., Sauter, M., and Teutsch, G.: Simulation of the development of gypsum maze caves, Environ. Geol., 48, 296306, https://doi.org/10.1007/s00254-005-1276-4, 2005.

Buhmann, D. and Dreybrodt, W.: The kinetics of calcite dissolution and precipitation in geologically relevant situations of karst areas, 2. Closed system, Chem. Geol., 53, 109-124, 1985.

Chaudhuri, A., Rajaram, H., Viswanathan, H., Zyvoloski, G., and Stauffer, P.: Buoyant convection resulting from dissolution and permeability growth in vertical limestone fractures, Geophys. Res. Lett., 36, L03401, https://doi.org/10.1029/2008GL036533, 2009.

Chaudhuri, A., Rajaram, H., and Viswanathan, H.: Earlystage hypogene karstification in a mountain hydrologic system: A coupled thermohydrochemical model incorporating buoyant convection, Water Resour. Res., 49, 5880-5899, https://doi.org/10.1002/wrcr.20427, 2013.

Cheung, W. and Rajaram, H.: Dissolution finger growth in variable aperture fractures: Role of the tip-region flow field, Geophys. Res. Lett., 29, 32-31-32-34, https://doi.org/10.1029/2002GL015196, 2002.

De Simoni, M., Sanchez-Vila, X., Carrera, J., and Saaltink, M. W.: A mixing ratios-based formulation for multicomponent reactive transport, Water Resour. Res., 43, W07419, https://doi.org/10.1029/2006WR005256, 2007.

Dreybrodt, W.: Processes in karst systems: physics, chemistry, and geology, Springer-Verlag, Berlin, New York, xii, 288 pp., 1988.
Dreybrodt, W.: The role of dissolution kinetics in the development of karst aquifers in limestone - A model simulation of karst evolution, J. Geol., 98, 639-655, 1990.

Dreybrodt, W.: Principles of early development of karst conduits under natural and man-made conditions revealed by mathematical analysis of numerical models, Water Resour. Res., 32, $2923-$ 2935, https://doi.org/10.1029/96WR01332 1996.

Dreybrodt, W. and Gabrovšek, F.: Dynamics of wormhole formation in fractured limestones, Hydrol. Earth Syst. Sci., 23, 1995-2014, https://doi.org/10.5194/hess-23-1995-2019, 2019.

Dreybrodt, W., Gabrovšek, F., and Romanov, D.: Processes of speleogenesis: A modeling approach, Carsologica, edited by: Gabrovšek, F., Založba ZRC, Ljubljana, 375 pp., 2005.

Eisenlohr, L., Meteva, K., Gabrovšek, F., and Dreybrodt, W.: The inhibiting action of intrinsic impurities in natural calcium carbonate minerals to their dissolution kinetics in aqueous $\mathrm{H}_{2} \mathrm{O}-\mathrm{CO}_{2}$ solutions, Geochim. Cosmochim. Ac., 63, 989-1001, 1999.

Gabrovšek, F. and Dreybrodt, W.: A model of the early evolution of karst aquifers in limestone in the dimensions of lenght and depth, J. Hydrol., 240, 206-224, https://doi.org/10.1016/S00221694(00)00323-1, 2001.

Gabrovšek, F. and Dreybrodt, W.: Karstification in unconfined limestone aquifers by mixing of phreatic water with surface water from a local input: A model, J. Hydrol., 386, 130-141, https://doi.org/10.1016/j.jhydrol.2010.03.015, 2010.

Gong, X., Hou, W., Feng, D., Luo, Q., and Yang, X.: Modelling early karstification in future limestone geothermal reservoirs by mixing of meteoric water with crossformational warm water, Geothermics, 77, 313-326, https://doi.org/10.1016/j.geothermics.2018.10.009, 2019.

Groves, C. G. and Howard, A. D.: Early development of karst systems, 1. Preferential flow path enlargement under laminar-flow, Water Resour. Res., 30, 2837-2846, 1994.

Hanna, R. B. and Rajaram, H.: Influence of aperture variability on dissolutional growth of fissures in karst formations, Water Resour. Res., 34, 2843-2853, 1998.

Jeong, C. H., Kim, H. J., and Lee, S. Y.: Hydrochemistry and genesis of CO2-rich springs from Mesozoic granitoids and their adjacent rocks in South Korea, Geochem. J., 39, 517-530, https://doi.org/10.2343/geochemj.39.517, 2005.

Kaufmann, G.: Modelling unsaturated flow in an evolving karst aquifer, J. Hydrol., 276, 53-70, 2003.

Kaufmann, G.: Modelling karst aquifer evolution in fractured, porous rocks, J. Hydrol., 543, 796-807, https://doi.org/10.1016/j.jhydrol.2016.10.049, 2016.

Kaufmann, G. and Romanov, D.: Modelling speleogenesis in soluble rocks: A case study from the Permian Zechstein sequences exposed along the southern Harz Mountains and the Kyffhäuser Hills, German, Acta Carsologica, 48, 173-197, https://doi.org/10.3986/ac.v48i2.7282, 2019.

Kaufmann, G., Romanov, D., and Hiller, T.: Modeling threedimensional karst aquifer evolution using different matrix-flow contributions, J. Hydrol., 388, 241-250, 2010.

Kaufmann, G., Gabrovšek, F., and Romanov, D.: Deep conduit flow in karst aquifers revisited, Water Resour. Res., 50, 4821-4836, https://doi.org/10.1002/2014wr015314, 2014.

Klimchouk, A.: Hypogene Speleogenesis: Hydrogeological and Morphogenetic Perspective, National Cave and Karst Research 
Institute, Special Paper National Cave and Karst Research Institute, Carlsbad, 106 pp., 2007.

Klimchouk, A.: Speleogenesis - Hypogene, in: Encyclopedia of Caves (Third Edition), edited by: White, W. B., Culver, D. C., and Pipan, T., Academic Press, chap. 14, 974-988, 2019.

Klimchouk, A., Palmer, A. N., Waele, J. D., Auler, A. S., and Audra, P.: Hypogene Karst Regions and Caves of the World, in: Cave and Karst Systems of the World, edited by: LaMoreaux, J. W., Springer, Cham, 911 pp., 2017.

Klimchouk, A. B.: Hypogene Speleogenesis, in: Treatise on Geomorphology, edited by: Shroder, J. F., Academic Press, San Diego, chap. 6.19, 220-240, 2013.

Klimchouk, A. B.: The Karst Paradigm: Changes, Trends and Perspectives, Acta Carsologica, 44, 289-313, https://doi.org/10.3986/ac.v44i3.2996, 2016.

Laabidi, E. and Bouhlila, R.: Nonstationary porosity evolution in mixing zone in coastal carbonate aquifer using an alternative modeling approach, Environ. Sci. Pollut. R., 22, 10070-10082, https://doi.org/10.1007/s11356-015-4207-2, 2015.

Li, S., Kang, Z., Feng, X.-T., Pan, Z., Huang, X., and Zhang, D.: Three-Dimensional Hydrochemical Model for Dissolutional Growth of Fractures in Karst Aquifers, Water Resour. Res., 56, e2019WR025631, https://doi.org/10.1029/2019wr025631, 2020.

Palmer, A. N.: Origin and morphology of limestone caves, Geol. Soc. Am. Bull., 103, 1-21, https://doi.org/10.1130/00167606(1991)103\%3C0001:OAMOLC\%3E2.3.CO;2, 1991.

Palmer, A. N.: Hydrogeologic control of cave patterns, in: Speleogenesis: Evolution of karst aquifers, edited by: Klimchouk, A., Ford, D. C., Palmer, A., and Dreybrodt, W., National Speleological Society, Huntsville, 77-90, 2000.

Palmer, A. N.: Support for a sulfuric acid origin for caves in the Guadalupe Mountains, New Mexico, in: Caves and Karst of Southeastern New Mexico, edited by: Land, L., Lueth, V. W., Raatz, W., Boston, P., and Love, D. L., NMGS 57th Fall Field Conference, New Mexico Geological Society, Socorro, Mew Mexico, USA, 159-202, 2006.
Palmer, A. N.: Cave geology, Cave Books, Dayton, Ohio, vi, 454 pp., 2007.

Palmer, A. N.: 6.20 Sulfuric Acid Caves: Morphology and Evolution, in: Treatise on Geomorphology, edited by: Shroder, J. F., Academic Press, San Diego, 241-257, 2013.

Palmer, A. N.: Hypogenic Versus Epigenic Aspects of the Black Hills Caves, South Dakota, in: Hypogene Karst Regions and Caves of the World, edited by: Klimchouk, A., N. Palmer, A., De Waele, J., S. Auler, A., and Audra, P., Springer International Publishing, Cham, 601-615, 2017.

Palmer, A. N. and Palmer, N. V.: Geologic history of Black Hills caves, South Dakota, NSS Bull., 51, 72-99, 1989.

Rajaram, H., Cheung, W., and Chaudhuri, A.: Natural analogs for improved understanding of coupled processes in engineered earth systems: examples from karst system evolution, Curr. Sci. India, 97, 1162-1176, 2009.

Rehrl, C., Birk, S., and Klimchouk, A. B.: Conduit evolution in deep-seated settings: Conceptual and numerical models based on field observations, Water Resour. Res., 44, W11425, https://doi.org/10.1029/2008WR006905, 2008.

Romanov, D. and Dreybrodt, W.: Evolution of porosity in the saltwater-freshwater mixing zone of coastal carbonate aquifers: An alternative modelling approach, J. Hydrol., 329, 661-673, https://doi.org/10.1016/j.jhydrol.2006.03.030, 2006.

Siemers, J. and Dreybrodt, W.: Early development of karst aquifers on percolation networks of fractures in limestone, Water Resour. Res., 34, 409-419, 1998.

Svensson, U. and Dreybrodt, W.: Dissolution kinetics of natural calcite minerals in $\mathrm{CO}_{2}$-water systems approaching calcite equilibrium, Chem. Geol., 100, 129-145, https://doi.org/10.1016/00092541(92)90106-F, 1992.

Szymczak, P. and Ladd, A. J. C.: Wormhole formation in dissolving fractures, J. Geophys. Res.-Sol. Ea., 114, B06203, https://doi.org/10.1029/2008JB006122, 2009. 